
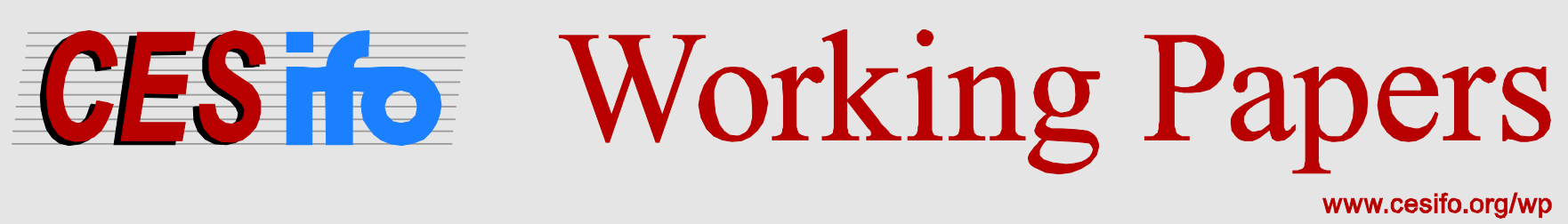

\title{
Compensated Discrete Choice with Particular Reference to Labor Supply
}

\author{
John K. Dagsvik \\ Steinar Strøm \\ Marilena Locatelli
}

CESIFO WORKING PAPER NO. 4591

CATEGORY 4: LABOUR MARKETS

JANUARY 2014

An electronic version of the paper may be downloaded

- from the SSRN website:

- from the RePEc website:

- from the CESifo website:

WWW.SSRN.com

www.RePEc.org

www.CESifo-group.org/wp 


\title{
Compensated Discrete Choice with Particular Reference to Labor Supply
}

\begin{abstract}
Dagsvik and Karlström (2005) have demonstrated how one can compute Compensating Variation and Compensated Choice Probabilities by means of analytic formulas in the context of discrete choice models. In this paper we offer a new and simplified derivation of the compensated probabilities. Subsequently, we discuss the application of this methodology to compute compensated labor supply responses (elasticities) in a particular discrete choice labor supply model. Whereas the Slutsky equation holds in the case of the standard microeconomic model with deterministic preferences, this is not so in the case of random utility models. When the non-labor income elasticity is negative the Slutsky equation implies that the compensated wage elasticity is higher than the uncompensated one. In contrast, in our random utility model we show empirically that in a majority of cases the uncompensated wage elasticity is in fact the highest one. We also show that when only the deterministic part of the utility function is employed to yield optimal hours and related elasticities, these elasticities are numerically much higher and decline more sharply across deciles than the random utility ones.
\end{abstract}

JEL-Code: J220, C510.

Keywords: female labor supply, compensated discrete choice.

John K. Dagsvik

Statistics Norway \& the Frisch Centre

Oslo / Norway

john.dagsvik@ssb.no

\author{
Steinar Strøm \\ The Frisch Centre \\ Oslo / Norway \\ steinar.strom@econ.uio.no
}

\author{
Marilena Locatelli \\ University of Turin and the Frisch Centre, Oslo \\ Turin / Italy \\ marilena.locatelli@unito.it
}

10 December, 2013

We acknowledge financial support from the Research Council of Norway (the tax research program), from research grants from the Department of Economics, University of Oslo, and from the Frisch Centre. 


\section{Introduction}

In recent years labor supply analysis based on the theory of discrete choice and random utility formulations has become increasingly popular. A major reason is that discrete choice labor supply models are much more practical than the conventional continuous approach based on marginal calculus: see the surveys by Creedy and Kalb (2005) and Dagsvik et al. (2013). For example, with the discrete choice approach, it is easy to deal with non-linear and non-convex economic budget constraints, and to apply rather general functional forms of the utility representations. In the literature basically two versions of discrete models of labor supply have been proposed. Van Soest (1995) and van Soest et al. (2002) propose to analyzing labor supply as a standard discrete choice problem. Alternatively, Dagsvik (1994), Aaberge et al. (1995), Aaberge et al. (1999), with further work by Dagsvik and Strøm (2006), Dagsvik and Jia (2006) and Dagsvik and Jia (2013), propose to analyzing labor supply as a job choice problem, where the set of feasible jobs is individual-specific and latent.

The history of random utility models dates back at least to Thurstone's 1927 analysis. It was more than 30 years before these types of models were applied in economics: see Quandt (1956), Luce (1959), and McFadden (1973, 1978, 1981, 1984) for wide-ranging discussions of motivation, exposition, and application. An early analysis of the potential of the random utility approach within economics was provided by Quandt (1956). He confronted the established wisdom of the time by arguing that it might be better to define preferences in a probabilistic sense, thereby making the model more realistic by weakening the postulate of strict rationality.

In microeconomics, the theory of compensated (Hicksian) demand and supply plays an important role. Until recently there has been very little focus on a corresponding theory for random utility models. While it is fairly straightforward to compute uncompensated responses and elasticities in discrete choice models, computation of the corresponding compensated effects is not so easy. Dagsvik and Karlström (2005) have demonstrated how one can calculate compensating variation (CV) and compensated choice probabilities (Hicks choice probabilities) in random utility models in the general case where the deterministic part of the utility function may be non-linear in income. Kornstad and Thoresen (2006) and Dagsvik et al. (2009) have applied the methodology of Dagsvik and Karlström (2005) to compute welfare measures such as CV in the context of selected tax reforms.

The contribution of this paper is twofold. First, we show that the derivations of compensated probabilities and CV given by Dagsvik and Karlström (2005) can be substantially simplified in the case of random utility models with utilities that are non-linear in income. Second, we show how one can apply the methodology of Dagsvik and Karlström (2005) to compute Hicks choice probabilities and corresponding compensated elasticities. To this end we base our analysis on the model developed by Dagsvik and Strøm (2006). Specifically, we show how one can compute Hicks joint choice probabilities and corresponding elasticities of being in particular states before and after tax reforms or changes in wages. The states are nonworking, working in specific sectors and with different working loads. 
We report uncompensated as well as compensated wage elasticities, and also non-labor income elasticities. These calculations show that the compensated wage elasticities tend to be higher at the extensive margin than at the intensive margin, while the opposite is true for uncompensated wage elasticities. The elasticities vary considerably with wage levels (the higher the wage, the lower the elasticity) and with household characteristics. Moreover, the calculation of these three types of elasticities demonstrates the extent to which the Slutsky equation is violated for this type of model.

Finally, we calculate compensated elasticities based on the sample values that were used in estimating the model. As in the case above, we find that the mean uncompensated elasticities of expected hours with respect to wages exceed the compensated elasticities, which is inconsistent with the prediction from the Slutsky equation.

The paper is organized as follows. In the next section we provide a new and simplified version of some of the key results obtained by Dagsvik and Karlström (2005) regarding compensating variation and compensated choice probabilities. We then discuss special cases, such as binary and ternary choice settings. This will demonstrate the essential features of the methodology proposed by Dagsvik and Karlström (2005), especially in relation to the labor supply. In Section 3 we provide a brief description of the empirical labor supply model that is the main focus of our application and in Section 4 we give numerical results.

\section{Expenditure and compensated choice in random utility models}

In this section we review a fundamental result obtained by Dagsvik and Karlström (2005) and we provide a simplified proofs.

Consider a setting with a finite number of alternatives. Assume that the utility of alternative $j$ has the structure $U_{j}(y)=\log v_{j}(y)+\varepsilon_{j}$, where $v_{j}(y)$ is a positive, deterministic and monotonically increasing function of $y$ and may also depend on prices, non-pecuniary and alternative $j$ - specific attributes, whereas $\varepsilon_{j}$ is a stochastic term that is supposed to account for the effect on preferences from variables that are not observed by the researcher. ${ }^{4}$ To this end let $U_{j}^{0}=\log v_{j}^{0}+\varepsilon_{j}=\log v_{j}^{0}\left(y^{0}\right)+\varepsilon_{j}$ denote the ex-ante utility of alternative $j$, where $y^{0}$ denotes the initial income and $v_{j}^{0}(\cdot)$ is the deterministic term associated with the utility of alternative $j$ exante, and let $U_{j}(y)=\log v_{j}(y)+\varepsilon_{j}$ be the corresponding utility of alternative $j$ ex-post. The respective systematic terms $v_{j}^{0}(\cdot)$ and $v_{j}(\cdot)$ may differ due to exogenous changes in taxes or alternative specific attributes, suppressed in the notation here. Here it is assumed that the stochastic terms of the utility function are not affected by the reform. Let $J^{0}$ and $J$ denote the ex-ante and ex-post choice given that the ex-ante and ex-post

\footnotetext{
${ }^{4}$ With no loss of generality we apply the logarithm transformation for the sake of simplifying the expressions below.
} 
utility levels of the chosen alternatives are equal. Let $P^{H}(j, k)$ denote the joint compensated (Hicksian) probability of choosing alternative $j$ ex-ante and alternative $k$ ex-post under the condition that the respective utility levels of the chosen alternatives before and after the reform are the same. In other words,

$$
P^{H}(j, k)=P\left(U_{j}^{0}=\max _{r} U_{r}^{0}, U_{k}(Y)=\max _{r} U_{r}(Y), \max _{r} U_{r}^{0}=\max _{r} U_{r}(Y)\right),
$$

where $Y$ is the expenditure function that yields the income required to maintain the utility level equal to the original utility level. Although suppressed in the notation, it is implicit that the expenditure function depends on the ex ante utility level as well as ex ante and ex post prices and other attributes. Furthermore, let

$$
\varphi(j, k, y)=P\left(U_{j}^{0}=\max _{r} U_{r}^{0}, U_{k}(Y)=\max _{r} U_{r}(Y), \max _{r} U_{r}^{0}=\max _{r} U_{r}(Y), Y \leq y\right) .
$$

The interpretation of the expression in (2.2) is as the joint probability of choosing alternative $j$ ex-ante, alternative $k$ ex-post, and $\{Y \leq y\}$, when the ex-post maximum utility is equal to the ex-ante maximum utility. Note that the income $Y$ is stochastic due to the utility function containing a stochastic term. Let $y_{j}$ be determined by $v_{j}^{0}\left(y^{0}\right)=v_{j}\left(y_{j}\right)$. That is, $y_{j}$ is the ex-post income that ensures that the ex-ante utility and ex-post utility of alternative $j$ are equal. Also let $\psi_{r}(y)=\max \left(v_{r}^{0}\left(y^{0}\right), v_{r}(y)\right)$. For simplicity we shall write $v_{j}^{0}\left(y^{0}\right)=v_{j}^{0}$. The following result was obtained by Dagsvik and Karlström (2005, Corollary 3.

\section{Theorem 1}

Assume an additive random utility model with independent error terms that have c.d.f. $\exp (-\exp (-x))$. Then

$$
\varphi(j, k, d y)=\frac{v_{j}^{0} v_{k}(d y)}{\left\{\sum_{r=1}^{m} \psi_{r}(y)\right\}^{2}}
$$

provided that $k \neq j$ and $y_{j} \geq y \geq y_{k}{ }^{5}$

The proof of Theorem 1 is given in Appendix A. As mentioned above, the proof given in Appendix A is a much simpler proof than one given by Dagsvik and Karström (2005).

For the sake of demonstrating the essential idea, we shall provide a brief outline of the argument of the proof: Consider the case with $m=3$. We have

$$
\left\{J^{0}=1, J=2\right\} \Leftrightarrow=\left\{\max \left(U_{2}^{0}, U_{3}^{0}\right) \leq U_{1}^{0}, \max \left(U_{1}(Y), U_{3}(Y)\right) \leq U_{2}(Y)=U_{1}^{0}\right\} .
$$

For $j$ to be the most preferred alternative ex-ante and $k$ the most preferred alternative ex-post, one must have $U_{2}(Y)=U_{1}^{0}>U_{2}^{0}$. Furthermore, since alternative 2 is the most preferred one ex-post, $U_{2}(Y)>U_{1}(Y)$, which

\footnotetext{
${ }^{5}$ As usual, the notation $d y$ means $(y, y+d y)$.
} 
implies that $U_{1}(Y)<U_{1}^{0}$. Hence, the event $\left\{U_{2}(y)=U_{1}^{0}\right\}$ implies that $\left\{U_{1}(y) \leq U_{1}^{0}, U_{2}^{0} \leq U_{1}^{0}\right\}$. Accordingly, the formula above yields

$$
\left\{J^{0}=1, J=2, Y=y\right\} \Leftrightarrow\left\{\max \left(U_{3}^{0}, U_{3}(y)\right) \leq U_{1}^{0}=U_{2}(y)\right\} .
$$

The last equation represents a key relation for deriving corresponding probabilities. As shown in Appendix A one can now readily calculate

$$
\begin{aligned}
& =P\left(\max \left(U_{3}^{0}, U_{3}(y)\right) \leq U_{1}^{0}, U_{2}(y) \leq U_{1}^{0} \leq U_{2}(y+\Delta y) \mid U_{1}^{0}=x\right) \\
& =P\left(\max \left(U_{3}^{0}, U_{3}(y)\right) \leq x, U_{2}(y) \leq x \leq U_{2}(y+\Delta y)\right)
\end{aligned}
$$

where $\Delta y$ is a small positive value. Note that the expression above is completely general and does not depend on the assumption of independent extreme value distributed random terms, so it is not hard to see how one can extend the result of Theorem 1 to the case with correlated error terms. In the case with independent error terms one has that

$$
P\left(\max \left(U_{3}^{0}, U_{3}(y)\right) \leq x, U_{2}(y) \leq x \leq U_{2}(y+\Delta y)\right)=P\left(\max \left(U_{3}^{0}, U_{3}(y)\right) \leq x\right) P\left(U_{2}(y) \leq x \leq U_{2}(y+\Delta y)\right)
$$

which simplifies the subsequent calculations further. By using the relation

$$
P\left(J^{0}=1, J=2, Y \in[y, y+d y)\right)=E P\left(\max \left(U_{2}^{0}, U_{3}^{0}\right) \leq U_{1}^{0}, \max \left(U_{1}(Y), U_{3}(Y)\right) \leq U_{2}(Y), Y \in[y, y+\Delta y) \mid U_{1}^{0}\right)
$$

one can obtain the desired choice probabilities.

The results in the following corollaries are also given in Dagsvik and Karlström (2005), but the proofs given here are considerably simpler.

\section{Corollary 1}

Under the assumptions of Theorem 1 the Hicksian (compensated) choice probabilities are given by

$$
P^{H}(j, k)=v_{j}^{0} \int_{y_{k}}^{y_{j}} \frac{v_{k}(d y)}{\left\{\sum_{r=1}^{m} \psi_{r}(y)\right\}^{2}}
$$

when $k \neq j$ and $y_{j}>y_{k}$. In the case where $j$ and $k$ are distinct and $y_{j}<y_{k}$ then $P^{H}(j, k)=0$. Furthermore, when $j=k$, then

$$
P^{H}(j, j)=\frac{v_{j}^{0}}{\sum_{r=1}^{m} \psi_{r}\left(y_{j}\right)} .
$$

The proof of Corollary 1 is given in Appendix A. 


\section{Corollary 2}

Under the assumptions of Theorem 1 the probability density, $\gamma(x)$ of $Y$, is given by

$$
\gamma(y)=\sum_{j, k} 1\left\{y_{j} \geq y \geq y_{k}\right\} \partial \varphi(j, k, y) / \partial y=\frac{\sum_{j} 1\left\{y_{j} \geq y\right\} v_{j}^{0} \sum_{r=1}^{m} v_{k}^{\prime}(y)}{\left\{\sum_{r=1}^{m} \psi_{r}(y)\right\}^{2}}
$$

provided the deterministic parts of the utility function are continuously differentiable.

The proof of Corollary 2 is given in Appendix A.

The corresponding Compensating Variation (CV) follows from the expenditure function by the relation $C V=y^{0}-Y$. From the results above one can obtain the corresponding c.d.f. of the expenditure function.

\section{Corollary 3}

Under the assumptions of Theorem 1 with $y<y_{j}$, we have

$$
P\left(J^{0}=j, Y>y\right)=\frac{v_{j}^{0}}{\sum_{r=1}^{m} \psi_{r}(y)} .
$$

The proof of Corollary 3 is given in Appendix A.

Dagsvik and Karlström (2005) prove the result of Corollary 3 (their Theorem 3) by a direct argument. It may now be instructive to look at a couple of special cases, namely the binary and ternary cases.

\subsection{The binary case}

In order to provide intuition into the formalism developed above, we shall now consider the case with two alternatives (alternatives one and two) in more detail. From (2.2) it follows by straightforward integration that when $y_{1}>y_{2}$

$$
P^{H}(1,2)=v_{1}^{0} \int_{y_{2}}^{y_{1}} \frac{v_{2}(d y)}{\left\{v_{1}^{0}+v_{2}(y)\right\}^{2}}=\frac{v_{1}^{0}}{v_{1}^{0}+v_{2}^{0}}-\frac{v_{1}^{0}}{v_{1}^{0}+v_{2}\left(y_{1}\right)} .
$$

According to (2.4), $P^{H}(2,2)$ is given by

$$
P^{H}(2,2)=\frac{v_{2}^{0}}{\sum_{k=1}^{2} \psi_{k}\left(y_{2}\right)}=\frac{v_{2}^{0}}{v_{1}^{0}+v_{2}^{0}} .
$$

Consequently, it follows that the ex post compensated probability of choosing alternative 2 is given by 


$$
P_{2}^{H}=P^{H}(1,2)+P^{H}(2,2)=\frac{v_{2}\left(y_{1}\right)}{v_{1}^{0}+v_{2}\left(y_{1}\right)}
$$

in this case. The corresponding ex-ante probability of choosing alternative 2 is given by

$$
P_{2}=\frac{v_{2}^{0}}{v_{1}^{0}+v_{2}^{0}} \text {. }
$$

Thus it follows that the compensated effect, when measured by the relative change $\left(P_{2}^{H}-P_{2}\right) / P_{2}$, is given by

$$
\begin{aligned}
& \frac{P_{2}^{H}-P_{2}}{P_{2}}=\left(\frac{v_{2}\left(y_{1}\right)}{v_{1}^{0}+v_{2}\left(y_{1}\right)}-\frac{v_{2}^{0}}{v_{1}^{0}+v_{2}^{0}}\right) / P_{2} \\
& =\frac{v_{2}\left(y_{1}\right)-v_{2}^{0}}{v_{1}^{0}+v_{2}\left(y_{1}\right)}=\frac{v_{2}\left(y_{1}\right)-v_{2}\left(y_{2}\right)}{v_{1}^{0}+v_{2}\left(y_{1}\right)}>0
\end{aligned}
$$

when $y_{1}>y_{2}$.

In the case where $y_{1} \leq y_{2}, P^{H}(1,2)=0$ and $P_{2}^{H}=P^{H}(2,2)$, so that we now obtain

$$
P_{2}^{H}=P^{H}(2,2)=\frac{v_{2}^{0}}{v_{2}^{0}+v_{1}\left(y_{2}\right)} .
$$

Hence, in the case with $y_{1} \leq y_{2}$,

$$
\frac{P_{2}^{H}-P_{2}}{P_{2}}=\frac{v_{1}^{0}-v_{1}\left(y_{2}\right)}{v_{2}^{0}+v_{1}\left(y_{2}\right)}=\frac{v_{1}\left(y_{1}\right)-v_{1}\left(y_{2}\right)}{v_{2}^{0}+v_{1}\left(y_{2}\right)} \leq 0 .
$$

Consider next the special case with only a reduction in the price (or cost) of alternative 2 while other attributes remain fixed. This implies that $v_{1}(y)=v_{1}^{0}(y)$ in this case, so that $y_{1}=y^{0}$. Since $v_{2}(y)>v_{2}^{0}(y)$ for any $y$, and $y_{2}$ is determined by $v_{2}\left(y_{2}\right)=v_{2}^{0}\left(y^{0}\right)$, it must be the case that $y_{2}<y^{0}=y_{1}$. According to (2.12), this means that the compensated price elasticity $\left(P_{2}^{H}-P_{2}\right) / P_{2}$ can never be negative in this case, which is intuitive.

\subsection{The ternary case}

Consider finally the case with three alternatives: that is, $m=3$. Then (2.4) reduces to

$$
P^{H}(j, k)==v_{j}^{0} \int_{y_{k}}^{y_{j}} \frac{v_{k}(d y)}{\left\{\sum_{r=1}^{3} \psi_{r}(y)\right\}^{2}},
$$

for $j, k=1,2,3$, and distinct $j$ and $k$. Suppose, for example, that $y_{1}>y_{3}>y_{2}$. It then follows that $P^{H}(1,2)>0$, $P^{H}(1,3)>0, P^{H}(3,2)>0$, whereas $P^{H}(2,3)=P^{H}(3,1)=P^{H}(2,1)=0$. From this we obtain 


$$
\begin{aligned}
& P^{H}(3,2)=v_{3}^{0} \int_{y_{3}}^{y_{1}} \frac{v_{2}(d y)}{\left\{v_{1}^{0}+v_{2}(y)+v_{3}^{0}\right\}^{2}} \\
& =\frac{v_{3}^{0}}{v_{1}^{0}+v_{2}\left(y_{3}\right)+v_{3}^{0}}-\frac{v_{3}^{0}}{v_{1}^{0}+v_{2}\left(y_{1}\right)+v_{3}^{0}} \\
& =\frac{v_{3}^{0}\left(v_{2}\left(y_{1}\right)-v_{2}\left(y_{1}\right)\right)}{\left(v_{1}^{0}+v_{2}\left(y_{3}\right)+v_{3}^{0}\right)\left(v_{1}^{0}+v_{2}\left(y_{1}\right)+v_{3}^{0}\right)} .
\end{aligned}
$$

However, one cannot in general not express the integral in (2.13) on closed form. The ex-post Hicksian probability of choosing alternative 2 equals

$$
P_{2}^{H}=P^{H}(1,2)+P^{H}(3,2)+P^{H}(2,2),
$$

and similarly for the other cases. Since $P^{H}(3,1)=P^{H}(2,1)=0$, we get for alternative 1 that

$$
P_{1}^{H}=P^{H}(1,1)=\frac{v_{1}^{0}}{v_{1}^{0}+v_{2}\left(y_{1}\right)+v_{3}\left(y_{1}\right)} .
$$

\subsection{Examples of compensated effects in discrete labor supply models}

Consider now the case of a model for labor force participation (binary case, $j=1,2$ ) and subsequently a model for labor force participation and choice of working in one of two sectors (ternary case, $j=1,2,3$ ).

\section{Example 1: Labor force participation (the binary case)}

Consider first the choice model of whether or not to work. Let $w$ an $I$ be the agent's wage and non-labor income. Let $f(h w, I)$ denote income after tax, where $h=1$ if working and $h=0$ otherwise. Let $U_{1}(y)=u_{1}(f(0, y))+\varepsilon_{1}$ be the agent's utility of not working and $U_{2}(y)=u_{2}(f(w, y))+\varepsilon_{2}$, the utility of working, where $u_{j}(C)$ is a deterministic function and the random error term $\varepsilon_{j}, j=1,2$, are supposed to account for unobserved heterogeneity in preferences across alternatives and agents. The agent will work if $U_{2}(y)>U_{1}(y)$. In this example it is assumed that the agent has no problem with finding a job, and consequently being employed will therefore be determined solely by the agent's preferences.

Consider now the effect of a change in economic incentives (such as a wage increase or a tax reform) that makes the working alternative more (or less) attractive. As above we assume in the following hat the random part of the utility function is kept fixed under the reforms. In other words, the results are to be interpreted as conditional on the unobservable. Let $w^{0}, f^{0}$ be the ex-ante wage and tax system, and $w, f$, the corresponding wage and tax system ex-post. Moreover, let $Y$ be the non-labor income that makes the ex-post indirect utility equal to the ex-ante indirect utility. Using the notation in section 2.1 , let 
$\log v_{j}^{0}\left(y^{0}\right)=\log v_{j}^{0}=u_{j}\left(f^{0}\left((j-1) w^{0}, y^{0}\right)\right), U_{j}^{0}=\log v_{j}^{0}\left(y^{0}\right)+\varepsilon_{j}, \log v_{j}(Y)=u_{j}(f((j-1) w, Y))$, and $U_{j}(Y)=\log v_{j}(Y)+\varepsilon_{j}$, for $j=1,2$. Thus $U_{j}^{0}$ is the ex-ante utility of being in labor market state $j$ and $U_{j}(Y)$ the corresponding ex-post utility. The random parts, $\varepsilon_{j}, j=1,2$, are assumed i.i. extreme value distributed across alternatives. The deterministic utilities may also depend on other alternative specific attributes. Let $y_{\mathrm{j}}$ be defined by $v_{j}^{0}\left(y^{0}\right)=v_{j}\left(y_{j}\right), j=1,2$. The compensated probability of "working" ("not working") can now be analyzed as outlined above in Section 2.1. In particular, it follows that the compensated wage elasticity will never be nonpositive.

\section{Example 2: A two-sector labor supply model (the ternary case)}

Consider next the following two-sector labor supply model. In this case there are three alternatives: "not working" (1), "working in the public sector" (2), and "working in the private sector" (3). Similarly to the previous example the only working option in both sectors is to work full time. As above, let $U_{1}$ be the utility of not working, $U_{2}$ the utility of working in the public sector and $U_{3}$ the utility of working in the private sector. Assume that $U_{1}(y)=u_{1}(f(0, y))+\varepsilon_{1}$ and $U_{j}(y)=u_{j}\left(f\left(w_{j}, y\right)\right)+\varepsilon_{j}$ for $j=2,3$, where $w_{j}$ is the wage of sector $j$. Let $\log v_{1}(y)=u_{1}(f(0, y))$ and $\log v_{j}(y)=u_{j}\left(f\left(w_{j}, y\right)\right)$, for $j=2,3$. As with the analysis in the previous example, let $U_{j}^{0}=\log v_{j}^{0}\left(y^{0}\right)+\varepsilon_{j}$ be the ex-ante utility representation and $U_{j}(Y)=\log v_{j}(Y)+\varepsilon_{j}$ the corresponding ex-post utility representation. The analysis now proceeds in a similar way to the ternary case discussed above.

\section{Compensated choice in a labor supply model with latent choice sets of available jobs}

In this section we consider compensated choice probabilities for the discrete labor supply model for married women with latent choice constraint developed by Dagsvik (1994) and Dagsvik and Strøm (2006), see also Dagsvik et al. (2013). The two-sector labor supply model is outlined in Appendix B. The wage income of the husband is assumed to be exogenously given. The household derives utility from household consumption, here set equal to household disposable income, leisure and non-pecuniary latent attributes of jobs.

Let $z=1,2 \ldots$, be an indexation of the jobs and let $z=0$ represent not working. The utility function is assumed to have the form

$$
U(C, h, z)=\log v(C, h)+\varepsilon(z),
$$


where $(C, h)$ denotes disposable income and annual hours of work and $v(\cdot)$ is a suitable positive deterministic function. Let $B(h)$ be the set of jobs with hours of work $h$ that are available to the agent. Let $D$ be the set of feasible hours, which here is assumed to be finite. The sets $B(h), h \in D$, are individual-specific and latent. The terms $\{\varepsilon(z)\}$ are positive sector- and job-specific random taste shifters. The taste shifter accounts for unobserved individual characteristics and unobserved job-specific attributes. These taste shifters, $\{\varepsilon(z)\}$, are assumed to be i.i.d. across jobs and agents, with c.d.f. $\exp \left(-e^{-x}\right)$, for real $x$. The reason why the index $z$ enters the utility function is that job-specific attributes beyond wage and hours of work may affect the utility of the agents. For given hours of work $h$ and wage rate $w$, disposable household income is given by $C=f(h w, I)$, where $f(\cdot)$ is a function that transforms pre-tax incomes into after-tax incomes, $w$ is the woman's wage and $I$ denotes non-labor income. Let $\theta$ be a measure that represents the number of jobs available to the agent and $g(h)$ the fraction of jobs with hours of work that are available to the agent. Thus $\theta g(h)$ is the number of jobs in the latent set $B(h)$. We call $\theta g(h)$ the opportunity measure of the agent. From (3.1) it follows that the highest utility the agent can attain, given that hours of work are equal to $h$, is obtained by

$$
V(h, y)=\max _{z \in B(h)} U(f(h w, y), h, z)=\log v(f(h w, y), h)+\max _{z \in B(h)} \varepsilon(z)=\log (v(f(h w, y), h) \theta g(h))+\eta(h)
$$

where the error terms $\{\eta(h)\}$ have the same distributional properties as $\{\varepsilon(z)\}$. The last equality in (3.2) follows because the distributional assumptions about the random error terms imply that

$$
\eta(h)=\max _{z \in B(h)} \varepsilon(z)-\log (\theta g(h))
$$

has the same distribution as $\varepsilon(1)$. This property follows readily from the extreme value distributional assumption, but to make the paper self-contained a proof of this property is given in Appendix A. Thus, formally, the utility maximization (with respect to hours of work) in the presence of this type of latent constraint can be achieved from the corresponding unconstrained case by modifying the structural part of the utility function, $v(f(h w, I), h)$, by multiplication of $\theta g(h)$.

Let $\varphi(h)$ be the probability (uncompensated) of choosing hours of work $h$ (for a utility maximizing agent). From (3.2) it follows immediately from the theory of discrete choice that

$$
\varphi(h)=P\left(V(h, I)=\max _{x \in D \cup\{0\}} V(x, I)\right)=\frac{v(f(h w, I), h) g(h) \theta}{v(f(0, I), 0)+\sum_{x>0, x \in D} v(f(x w, I), x) g(x) \theta}
$$

for $h>0$, see Dagsvik and Strøm (2006) or Dagsvik et al. (2013). For $h=0, \varphi(0)$ is obtained from (3.3) by replacing the numerator by $v(f(0, I), 0)$. Dagsvik and Jia (2013) discuss identification of this type of models and they show that the model is identified under the functional form assumptions described in Appendices A and B.

As in Section 2, consider a setting where a tax reform, a wage change, or some other change is introduced. For example, the framework above allows for changes in latent choice constraints through the 
opportunity measure $\theta g(h)$. Let $\left(f^{0}, w^{0}, \theta^{0} g^{0}(h)\right)$ and $(f, w, \theta g(h))$ denote the ex-ante and ex-post tax system wages and opportunity measures respectively. The corresponding compensated effects can now be calculated in a similar way to that outlined in Section 2. Let $y(h)$ be the real number that solves

$$
v\left(f^{0}\left(h w^{0}, I\right), h\right) \theta^{0} g^{0}(h)=v(f(h w, y(h)), h) \theta g(h)
$$

when $h$ is positive and

$$
v\left(f^{0}(0, I), 0\right)=v(f(0, y(0)), 0)
$$

when $h=0$. For short, let $V^{0}(h, y)$ and $V(h, y)$ denote the ex-ante and ex-post maximal utility given hours of work and non-labor income $(h, y)$. Define the joint compensated probability

$$
\begin{aligned}
& P^{H}\left(h^{0}, h\right) \\
& =P\left(\max _{x \in D \cup\{0\}} V^{0}(x, I)=V^{0}\left(h^{0}, I\right), V(h, Y)=\max _{x \in D \cup\{0\}} V(x, Y), \max _{x \in D \cup\{0\}} V^{0}(x, I)=\max _{x \in D \cup\{0\}} V(x, Y)\right\} .
\end{aligned}
$$

The probability defined in (3.4) is similar to the corresponding one defined in Section 2. It is the probability that the ex-ante labor supply is equal to $h^{0}$ and the ex-post supply is equal to $h$, when the ex-ante and ex-post utility levels are equal. It follows from Corollary 1 that

$$
P^{H}\left(h^{0}, h\right)=1\left\{y\left(h^{0}\right)>y(h)\right\} \int_{y(h)}^{y\left(h^{0}\right)} \frac{\theta^{0} g^{0}\left(h^{0}\right) \theta g(h) v\left(f^{0}\left(h^{0} w^{0}, I\right), h^{0}\right) v(f(h w, d y), h)}{K(y)^{2}},
$$

for $h \neq h^{0}$, and $h>0, \tilde{h}>0$, where the indicator notation 1\{\} means that $1\{y>x\}$ if $y>x$ and zero otherwise and

$$
K(y)=\max \left(v\left(f^{0}(0, I), 0\right), v(f(0, y), 0)\right)+\sum_{x \in D} \max \left[\theta^{0} g^{0}(x) v\left(f^{0}\left(x w^{0}, I\right), x\right), \theta g(x) v(f(x w, y), x)\right] .
$$

Recall that the choice probabilities in (3.1) and (3.5) allow for changes in the opportunity measure, where $\theta^{0} g^{0}(h)$ and $\theta g(h)$ denote the ex-ante and ex-post opportunity measures respectively. Furthermore, we get from Corollary 1 that

$$
P^{H}(h, h)=\frac{\left.\theta^{0} g^{0}(h) v\left(f^{0}\left(h w^{0}, I\right), h\right)\right)}{K(y(h))},
$$

for $h>0$. For $h^{0}=0, h>0$, it follows that

$$
P^{H}(0, h)=1\{y(0)>y(h)\} \int_{y(h)}^{y(0)} \frac{\theta g(h) v\left(f^{0}(0, I), 0\right) v(f(h w, d y), h)}{K(y)^{2}},
$$

and similarly for $h^{0}>0, h=0$. For $h=h^{0}=0$, we have 


$$
P^{H}(0,0)=\frac{\left.v^{0}\left(f^{0}(0, I), 0\right)\right)}{K(y(0))} .
$$

Let $\varphi^{0}(h)$ denote the ex-ante choice probability, which is obtained from (3.3) by inserting the initial tax system, wage, and opportunity distribution. The marginal ex-post compensated choice probability, $\varphi^{H}(h)$ is given by

$$
\varphi^{H}(h)=\sum_{x \in \bar{D}} P^{H}(x, h) .
$$

Hence the compensated relative change in the probability of choosing $h$ hours of work induced by the reform equals

$$
\frac{\varphi^{H}(h)-\varphi^{0}(h)}{\varphi^{0}(h)}
$$

The corresponding compensated change in the mean labor supply is given by

$$
\frac{\sum_{x \in D} x \varphi^{H}(x)-\sum_{x \in D} x \varphi^{0}(x)}{\sum_{x \in D} x \varphi^{0}(x)} .
$$

\section{Computation of selected compensated and uncompensated effects}

Here we report numerical results based on the two-sector discrete labor supply model developed by Dagsvik and Strøm (2006). In Appendix B we give a summary of the model. Summary statistics, tax functions, and estimates are given in Appendix C.

\subsection{Elasticities}

We have applied the model to compute compensated wage elasticities and uncompensated wage and income elasticities for 48 different cases. We have chosen three wage levels (NOK 1994): one that is low (NOK 70 per hour), one that is high (NOK 200 per hour), and one that is super-high (NOK 300 per hour). Non-labor income (which include the income of the husband) are NOK 50,000 (low), NOK 100,000 (lower than average), and NOK 200,000 (above average). The selected household characteristics are: "No child" or "two children", combined with woman's age equal to 30 years or 40 years. The results below demonstrate the extent of heterogeneity in the labor supply responses. Further detailed results can be found in Appendix D. The levels of participation and expected hours of work prior to the wage increase are given in Appendix E. The tables in Appendix E show that participation and hours worked, given the wage decline with non-labor income, number of children, and age. Hours worked increase with the wage level.

The elasticities vary to a great extent. The highest uncompensated elasticity of conditional expected hours with respect to the wage is above 4 (public sector) and 2.5 (the private sector) times higher than the lowest elasticity (Table 1). For the uncompensated elasticity of unconditional hours the ratios are around 8.5 (public 
sector) and 6 (private sector). The differences between the highest and lowest compensated elasticities are smaller (Table 2) than for the uncompensated. Table 3 shows that for the non-labor income elasticities the difference between the lowest and the highest elasticities is sizeable.

\section{Table 1. Uncompensated wage elasticities}

High: Woman aged 40, two children, non-labor income NOK 200,000, wage NOK70

Low: Woman aged 30, no children, non-labor income NOK 50,000, wage NOK 70

\begin{tabular}{llllllllll} 
Elasticity & \multicolumn{3}{l}{ Probability of working } & \multicolumn{3}{c}{ Conditional mean hours } & \multicolumn{3}{c}{ Unconditional mean hours } \\
\hline \multirow{3}{*}{ High } & All & Public & Private & All & Public & Private & All & Public & Private \\
\cline { 2 - 10 } Low & 0.620 & 0.670 & 0.465 & 0.649 & 0.660 & 0.599 & 1.309 & 1.374 & 1.093 \\
& 0.000 & 0.007 & -0.043 & 0.163 & 0.152 & 0.222 & 0.163 & 0.160 & 0.178
\end{tabular}

\section{Table 2. Compensated wage elasticities}

High: Woman aged 40, two children, non-labor income NOK 50,000, wage NOK 300

Low: Woman aged 30, no children, non-labor income NOK 50,000, wage NOK 70

\begin{tabular}{llllllllll} 
Elasticity & \multicolumn{3}{l}{ Probability of working } & \multicolumn{3}{c}{ Conditional mean hours } & \multicolumn{3}{c}{ Unconditional mean hours } \\
\hline \multirow{3}{*}{ High } & All & Public & Private & All & Public & Private & All & Public & Private \\
\cline { 2 - 10 } Low & 0.419 & 0.331 & 0.765 & 0.267 & 0.259 & 0.292 & 0.687 & 0.590 & 1.057 \\
& 0.131 & 0.135 & 0.119 & 0.186 & 0.174 & 0.254 & 0.318 & 0.310 & 0.368
\end{tabular}

\section{Table 3. Non-labor income elasticities}

High: Woman aged 30, no children, non-labor income NOK 200,000, wage NOK 200

Low: Woman aged 30, two children, non-labor income NOK 100,000, wage NOK 70

\begin{tabular}{llllllllll} 
Elasticity & \multicolumn{3}{c}{ Probability of working } & \multicolumn{3}{c}{ Conditional mean hours } & \multicolumn{3}{c}{ Unconditional mean hours } \\
\hline \multirow{3}{*}{ High } & All & Public & Private & All & Public & Private & All & Public & Private \\
\cline { 2 - 10 } Low & 0.000 & 0.000 & 0.000 & -0.010 & -0.010 & -0.013 & -0.010 & -0.010 & -0.013 \\
& -0.126 & -0.137 & -0.075 & -0.149 & -0.148 & -0.146 & -0.273 & -0.284 & -0.221
\end{tabular}

The uncompensated wage elasticities are higher at the intensive margin than at the extensive margin, with only two exceptions (out of 48 cases). The compensated wage elasticities are more equal at the extensive and the intensive margins, but with a weak tendency to be higher at the extensive margin. The non-labor income elasticities tend to be lowest (more negative) at the intensive margin.

The elasticities tend to decline with wage, in particular for women with two children. For example, for a woman aged 30 with two children and non-labor income NOK 200,000, the uncompensated elasticity of conditional expected hours (all sectors) declines from 0.634 (wage level NOK70) to 0.244 (wage level NOK 300 ) and the uncompensated elasticity of unconditional expected hours from 1.177 to 0.344 . For the same woman and for the same wage levels, the decline in compensated elasticity is smaller: The compensated 
elasticity of conditional expected hours drops from 0.410 to 0.266 , and the compensated elasticity of unconditional expected hours drops from 1.093 to 0.635 .

The participation elasticities are higher related to working in the private sector than in the public sector. The elasticities of conditional expected hours tend to be higher when the wage is low compared to when the wage is high. The reason is that when the wage is high the woman works long hours and hence the impact of a higher wage is lower compared to the case where the wage is low and initial hours are lower. This is particularly the case when the woman works in the private sector, where hours are less constrained.

If the woman has children the elasticities of conditional expected hours are higher compared to a childless woman. The reason is that the presence of small children reduces hours of work and hence the impact of a wage increase becomes stronger compared to a case for a childless women who works initially longer hours.

Recall that in the traditional deterministic microeconomic models the Slutsky equation holds: That is, the difference between the uncompensated and the compensated wage elasticities equals the non-labor income elasticity multiplied by the ratio of non-labor income to hours of work times the marginal wage. In random utility models, however, the Slutsky equation does not necessarily hold because choice behavior in this case is not determined by the usual marginal calculus. Table 4 below illustrates this feature. In particular, when nonlabor income is equal to NOK 200,000 the Slutsky relation is very far from being met. See Appendix D for more detailed results.

Table 4. Comparison between uncompensated, compensated, and non-labor income elasticities. Woman aged 40, two children, wage NOK 70

\begin{tabular}{|c|c|c|c|c|c|c|}
\hline \multirow[t]{2}{*}{ Elasticity } & \multicolumn{3}{|c|}{$\begin{array}{l}\text { Non-labor income NOK 50,000 } \\
\text { Conditional mean hours }\end{array}$} & \multicolumn{3}{|c|}{$\begin{array}{l}\text { Non-labor income NOK 200,000 } \\
\text { Conditional mean hours }\end{array}$} \\
\hline & All & Public & Private & All & Public & Private \\
\hline Uncompensated & 0.508 & 0.500 & 0.521 & 0.649 & 0.660 & 0.599 \\
\hline Compensated & 0.566 & 0.557 & 0.571 & 0.412 & 0.376 & 0.487 \\
\hline Non-labor incom & -0.145 & -0.143 & -0.146 & -0.116 & -0.118 & -0.108 \\
\hline
\end{tabular}

In Appendix $\mathrm{F}$ we show labor supply curves for a woman aged 30 and 40 with no children and two children. Notice that hours are along the vertical axis and wages along the horizontal axis. We show an uncompensated labor supply curve as well as a compensated. In Figures F.1 and F.2 we show the curves for the private and the public sector. The curves for the private sector are steeper and vary across shorter hours than the curves for the public sector. The uncompensated curves for both sectors taken together show how the expected hours, summed of the public and private sector using 
uncompensated and unconditional choice probabilities, vary with wage rate. The same is done for the compensated labor supply curve, but using compensated choice probabilities, see Figures F.3 and F.4. The curves are upward sloping and slightly steeper at low wages and slightly steeper for women with children than without children. Note that taxes are accounted for when calculating the supply curves.

\subsection{Numerical results using sample values}

This section contains numerical results for compensated wage elasticities for the two-sector model using sample values. This allows us to show how the compensated elasticities vary across deciles of the (endogenous) income distribution.

The income decile limits are calculated from the expected household disposable income, using the probabilities (in B.1, Appendix B). For each possible hour we have calculated the mean of the probabilities based on 50x50 draws from the normal distribution to simulate the random error terms in the wage equations. By aggregating across all possible hours and sectors (including the not working option), we are then able to simulate incomes, and hence the income decile limits. Within each decile we then use eqs. B.4- B.13 to calculate the relative change in compensated probabilities for each level of hours of work and sector, and finally we calculate weighted average over hours, given the sector, using the compensated probabilities as weights. Again, we have to make draws from the normal distribution to simulate the error terms in the wage equations since these enter in (eqs. B.4-B.13). In order to calculate the elasticity of working, we take the weighted average over all deciles and sectors. To calculate the elasticity of working in a specific sector we do a similar calculation.

In Tables 5-7 we give the uncompensated and the compensated elasticities related to an overall wage increase. Table 5 gives the elasticities of working, and working in the two sectors; Table 6 gives the elasticities of conditional expected hours, conditional on working and working in specific sectors: and Table 7 gives the elasticities of the unconditional expected hours (which is the sum of the two above).

Table 5. Aggregated wage elasticities of the probability of working, and of working in the public or private sector, across deciles in the household income distribution

\begin{tabular}{|c|c|c|c|c|c|c|}
\hline \multirow[b]{2}{*}{ Sector } & \multicolumn{3}{|c|}{ Uncompensated } & \multicolumn{3}{|c|}{ Compensated } \\
\hline & $1^{\text {st }}$ decile & $\begin{array}{l}2^{\text {nd }}-9^{\text {th }} \\
\text { decile }\end{array}$ & $10^{\text {th }}$ decile & $1^{\text {st }}$ decile & $\begin{array}{l}2^{\text {nd }}-9^{\text {th }} \\
\text { decile }\end{array}$ & $10^{\text {th }}$ decile \\
\hline All sectors & 0.2360 & 0.2805 & 0.2623 & 0.4170 & 0.4650 & 0.4752 \\
\hline Public & 0.0790 & 0.0854 & 0.0811 & 0.2840 & 0.2670 & 0.2495 \\
\hline Private & 0.3660 & 0.4880 & 0.4383 & 0.5232 & 0.6609 & 0.8180 \\
\hline
\end{tabular}

Table 6. Aggregate compensated wage elasticities of conditional expected hours in the public or private sector, across deciles in the household income distribution 


\begin{tabular}{|c|c|c|c|c|c|c|}
\hline \multirow[b]{2}{*}{ Sector } & \multicolumn{3}{|c|}{ Uncompensated } & \multicolumn{3}{|c|}{ Compensated } \\
\hline & $1^{\text {st }}$ decile & $\begin{array}{l}2^{\text {nd }}-9^{\text {th }} \\
\text { decile }\end{array}$ & $10^{\text {th }}$ decile & $1^{\text {st }}$ decile & $\begin{array}{l}2^{\text {nd }}-9^{\text {th }} \\
\text { decile }\end{array}$ & $10^{\text {th }}$ decile \\
\hline All sectors & 0.3523 & 0.3529 & 0.3511 & 0.3069 & 0.2963 & 0.3256 \\
\hline Public & 0.3700 & 0.3645 & 0.3655 & 0.3156 & 0.3052 & 0.324 \\
\hline Private & 0.3373 & 0.3354 & 0.3337 & 0.3021 & 0.2903 & 0.3409 \\
\hline
\end{tabular}

Table 7. Aggregate compensated wage elasticities of unconditional expected hours in the public or private sector, across deciles in the household income distribution

\begin{tabular}{|c|c|c|c|c|c|c|}
\hline \multirow[b]{2}{*}{ Sector } & \multicolumn{3}{|c|}{ Uncompensated } & \multicolumn{3}{|c|}{ Compensated } \\
\hline & $1^{\text {st }}$ decile & $\begin{array}{l}2^{\text {nd }}-9^{\text {th }} \\
\text { decile }\end{array}$ & $10^{\text {th }}$ decile & $1^{\text {st }}$ decile & $2^{\text {nd }}-9^{\text {th }}$ decile & $10^{\text {th }}$ decile \\
\hline All sectors & 0.5966 & 0.6433 & 0.6226 & 0.7238 & 0.7613 & 0.8009 \\
\hline Public & 0.4519 & 0.4531 & 0.4495 & 0.6005 & 0.5772 & 0.5734 \\
\hline Private & 0.7156 & 0.8399 & 0.7866 & 0.8253 & 0.9512 & 1.1590 \\
\hline
\end{tabular}

A striking result is that both types of elasticities of conditional expected hours seem to be nearly the same across deciles and sectors. This is, however, a consequence of the distribution of the household characteristics of the sample, because we have seen in the previous section that the corresponding compensated and uncompensated elasticities differ within particular population groups and for different wage levels. For the private sector the compensated elasticities at the extensive margin tend to be higher than at the intensive margin. This is in accordance with the results reported in the previous section. The elasticities indicate that utility constant overall wage increases shift labor into the private sector and toward longer hours. We note that the uncompensated elasticities of conditional hours exceed the compensated elasticities in both sectors and all deciles, except for the $10^{\text {th }}$ decile in the private sector. Thus these results also are inconsistent with the Slutsky equation.

Disregarding the stochastic components of the utility function Recall from (3.2) that

$$
V(h, y)=\log (v(f(h w, y), h) \theta g(h))+\eta(h)
$$

For positive $h$ and

$$
V(0, y)=\log (v(f(0, y), 0))+\eta(0)
$$

for $h=0$, where the error terms are independent of the systematic terms and have the same distribution as the original error terms associated with the latent attributes of the jobs. In Tables 8-10 we report the elasticities that follow when we use only the mean value of the above utility function to simulate behavior. In this case it follows from the utility function above that the utility maximizing problem becomes equivalent to maximizing 
the function $v(f(h w, y), h) \theta g(h)$. The motivation is to assess the significance of the stochastic elements of the utility function.

The elasticities in Tables 8 and 9 can be compared with the elasticities in Table 6 above. There are three important differences. First, both the uncompensated and compensated elasticities are numerically much higher than the elasticities that follow from the random utility model. Thus to conclude about wage and tax labor supply responses based on the deterministic parts of random utility models, might be quite misleading. Second, with the model represented by $(4.1 \mathrm{a}, \mathrm{b})$, the elasticities in this case decline substantially from the first decile of the income distribution to the higher deciles. In the random utility model such a distinct pattern does not exist. Third, the compensated elasticities are significantly higher than the uncompensated, which implies also sizeable negative income elasticities, as shown in Table 10. With the random utility models these are numerically much lower, as indicated in Section 4.1.

Table 8. Uncompensated wage elasticities, given participation

\begin{tabular}{lrrr}
\hline & \multicolumn{3}{l}{ Deciles } \\
\cline { 2 - 4 } Sector & $1^{\text {st }}$ decile & $2^{\text {nd }}-9^{\text {th }}$ decile & $10^{\text {th }}$ decile \\
\hline Both sector & 1.5907 & 0.8159 & 0.6887 \\
Public & 1.5035 & 0.7153 & 0.6204 \\
Private & 1.6585 & 0.9406 & 0.7570
\end{tabular}

Table 9. Compensated wage elasticities, given participation

\begin{tabular}{llrr}
\hline & \multicolumn{3}{c}{ Deciles } \\
\cline { 2 - 4 } \multicolumn{1}{c}{ Sector } & $1^{\text {st }}$ decile & $2^{\text {nd }}-9^{\text {th }}$ decile & $10^{\text {th }}$ decile \\
\hline Both sector & 1.7546 & 0.9271 & 0.7601 \\
Public & 1.6800 & 0.8255 & 0.6912 \\
Private & 1.8125 & 1.0529 & 0.8290
\end{tabular}

Table 10. Income elasticities, given participation

\begin{tabular}{lrrr}
\hline & \multicolumn{2}{c}{ Deciles } & \\
\cline { 2 - 4 } \multicolumn{1}{c}{ Sector } & $1^{\text {st }}$ decile & $2^{\text {nd }}-9^{\text {th }}$ decile & $10^{\text {th }}$ decile \\
\hline Both sector & -0.6152 & -0.2541 & -0.1904 \\
Public & -0.5633 & -0.2143 & -0.1714 \\
Private & -0.6555 & -0.3035 & -0.2094
\end{tabular}

\section{Conclusion}


A major goal of this paper is to simplify, and in so-doing clarify, the analytic results obtained by Dagsvik and Karlström (2005) regarding compensated choice probabilities and the distribution of CV for random utility models. We have shown how the proofs of key results in Dagsvik and Karlström (2005) can be considerably simplified. A further aim has been to show how the apparatus of Dagsvik and Karlström (2005) can be applied to compute compensated choice probabilities for a particular labor supply model developed by Dagsvik and Strøm (2006). Finally, we have computed compensated and uncompensated elasticities for selected household groups, as well as for the sample used to estimate the model, based on the estimated labor supply model of Dagsvik and Strøm (2006). The numerical results demonstrate that the uncompensated and compensated wage elasticities may vary considerably between agents. The uncompensated wage elasticities are higher at the intensive margin than at the extensive margin, while the opposite tends to be the case for compensated elasticities. Both types of elasticity tend to decline by wage level. In the case of our particular sector model, we have also demonstrated that stochastic error terms play a major role for the numerical results.

While the Slutsky equation holds for the conventional labor supply model, this is no longer the case for models based on the random utility theory. In this paper we have shown empirically the extent to which the Slutsky equation is violated in our selected examples.

\section{References}

Aaberge, R., J. K. Dagsvik and S. Strøm (1995): Labor Supply Responses and Welfare Effects of Tax Reforms. Scandinavian Journal of Economics, 97, 635-659.

Aaberge, R., U. Colombino and S. Strøm (1999): Labor Supply in Italy. An Empirical Analysis of Joint Household Decisions, with Taxes and Quantity Constraints. Journal of Applied Econometrics, 14, 403-422.

Creedy, J. and G. Kalb (2005): Discrete Hours Labour Supply Modeling: Specification, Estimation and Simulation. Journal of Economic Surveys, 19, 697-734.

Dagsvik, J. K. (1994): Discrete and Continuous Choice, Max-Stable Processes, and Independence from Irrelevant Attributes. Econometrica, 62, 1179-1205.

Dagsvik, J. K. and A. Karlström (2005): Compensating Variation and Hicksian Choice Probabilities in Random Utility Models that are Nonlinear in Income. Review of Economic Studies, 72, 57-76.

Dagsvik, J. K and S. Strøm (2006): Sectoral Labor Supply, Choice Restrictions and Functional Form. Journal of Applied Econometrics, 21, 803-826.

Dagsvik, J. K. and Z. Jia (2006): Labor Supply as a Choice among Latent Job Opportunities. Discussion Papers no 481, Statistiscs Norway.

Dagsvik, J. K., M. Locatelli and S. Strøm (2009): Tax Reform, Sector Specific Labor Supply and Welfare Effects. Scandinavian Journal of Economics, 111, 265-287.

Dagsvik, J. K., Z. Jia, T. Kornstad and T. O. Thoresen (2013): Theoretical and Practical Arguments for Modeling Labor Supply as a Choice among Latent Jobs. Journal of Economic Surveys, doi: 10.1111/joes.12003. 
Kornstad, T. and T. O. Thoresen (2006): Effects of Family Policy Reforms in Norway: Results from a Joint Labour Supply and Childcare Choice Microsimulation Analysis. Fiscal Studies, 27, 339-371.

Luce, R. D. (1959): Individual Choice Behavior. Wiley, New York.

McFadden, D. (1973): Conditional logit analysis of qualitative choice behavior. In P. Zarembka (ed), Frontiers in Econometrics, New York, Academic Press.

McFadden, D. (1978): Modelling the choice of residential location. In A. Karlqvist, L. Lundqvist, F. Snickars and J. J. Weibull (eds.), Spatial Interaction Theory and Planning Models. North Holland, Amsterdam.

McFadden, D. (1981): Econometric models of probabilistic choice. In C. Manski and D. McFadden (eds.), Structural Analysis of Discrete Data with Econometric Applications, MIT Press, Cambridge, Massachusetts.

McFadden, D. (1984): Econometric analysis of qualitative response models. In Z. Grilliches and M. D. Intriligator (eds.), Handbook of Econometrics, Vol. II, Elsevier Science, New York.

Quandt, R. E. (1956): A Probabilistic Theory of Consumer Behavior. Quarterly Journal of Economics, 70, 506536.

Statistics Norway (1994), Survey of Income and Wealth. www.ssb.no/emner/05/01/.

Statistics Norway (1995), Level of Living Conditions. www.ssb.no/emner/00/02/.

Thurstone, L. L. (1927): A Law of Comparative Judgment. Psychological Review, 79, 281-299.

Van Soest, A. (1995): A Structural Model of Family Labor Supply: A Discrete Choice Approach. Journal of Human Resources, 30, 63-88.

Van Soest, A., M. Das and X. Gong, (2002): A Structural Labour Supply Model with Flexible Preferences. Journal of Econometrics, 107, 345-374.

\section{Appendix A}

For convenience we first prove the following elementary Lemma.

\section{Lemma 1}

$$
\int_{-\infty}^{\infty} \exp \left(-e^{-x}(a+b)\right) e^{-2 x} b d x=\frac{b}{(a+b)^{2}}
$$

\section{Proof of Lemma 1:}

Integration by parts yields

$$
b \int_{-\infty}^{\infty} \exp \left(-e^{-x}(a+b)\right) e^{-2 x} d x=\left.\frac{b}{a+b}\right|_{-\infty} ^{\infty} e^{-x} \exp \left(-e^{-x}(a+b)\right)+\frac{b}{a+b} \int_{-\infty}^{\infty} \exp \left(-e^{-x}(a+b)\right) e^{-x} d x
$$




$$
=\frac{b}{a+b} \int_{-\infty}^{\infty} \exp \left(-e^{-x}(a+b)\right) e^{-x} d x=\frac{b}{(a+b)^{2}} .
$$

\section{Proof of Theorem 1:}

We shall first derive the proof of $P^{H}(1,2)$ for the case with $m=3$. Assume that $y_{2}<y_{1}$ and let $y \in\left[y_{2}, y_{1}\right]$. We have

$$
\begin{aligned}
\left\{J^{0}=\right. & 1, J=2, Y=y\} 1\left\{U_{1}^{0}=x\right\} \Leftrightarrow\left\{\max \left(U_{2}^{0}, U_{3}^{0}\right) \leq U_{1}^{0}, \max \left(U_{1}(Y), U_{3}(Y)\right) \leq U_{2}(Y), Y=y\right\} 1\left\{U_{1}^{0}=x\right\} \\
& =\left\{\max \left(U_{2}^{0}, U_{3}^{0}\right) \leq x, \max \left(U_{1}(y), U_{3}(y)\right) \leq U_{2}(y)=x\right\} 1\left\{U_{1}^{0}=x\right\} \\
& =\left\{\max \left(U_{3}^{0}, U_{3}(y)\right) \leq x, U_{2}(y)=x, U_{2}^{0} \leq x, U_{1}(y) \leq x\right\} 1\left\{U_{1}^{0}=x\right\} .
\end{aligned}
$$

Since $y_{2} \leq y \leq y_{1}$, it follows that $U_{1}(y) \leq U_{1}^{0}$ and $U_{2}(y) \geq U_{2}^{0}$. Hence, the event $\left\{U_{2}(y)=U_{1}^{0}=x\right\}$ implies that $\left\{U_{1}(y) \leq x, U_{2}^{0} \leq x\right\}$. Accordingly

$$
\left\{J^{0}=1, J=2, Y=y\right\} \Leftrightarrow\left\{\max \left(U_{3}^{0}, U_{3}(y)\right) \leq x, U_{2}(y)=x\right\} 1\left\{U_{1}^{0}=x\right\} .
$$

Thus, the corresponding probabilities are therefore given by

$$
\begin{aligned}
& P\left(J^{0}=1, J=k, Y \in[y, y+\Delta y) \mid U_{1}^{0}=x\right)=P\left(J^{0}=1, J=k, Y \in[y, y+\Delta y) \mid U_{1}^{0}=x\right) \\
& =P\left(\max \left(U_{3}^{0}, U_{3}(y)\right) \leq x, U_{2}(y) \leq x \leq U_{2}(y+\Delta y) \mid U_{1}^{0}=x\right)+o(\Delta y) \\
& =P\left(\max \left(U_{3}^{0}, U_{3}(y)\right) \leq x\right) P\left(U_{2}(y) \leq x<U_{2}(y+\Delta y)\right)+o(\Delta y) \\
& =P\left(\psi_{3}(y)+\varepsilon_{3} \leq x\right) P\left(v_{2}(y)+\varepsilon_{2} \leq x<v_{2}(y+\Delta y)+\varepsilon_{2}\right)+o(\Delta) \\
& =\exp \left(-e^{-x} \psi_{3}(y)\right)\left(\exp \left(-e^{-x} v_{2}(y)-\exp \left(-e^{-x} v_{2}(y+\Delta y)\right)\right)+o(\Delta)\right. \\
& =\exp \left(-e^{-x} \psi_{3}(y)\right) \exp \left(-e^{-x} v_{2}(y)\right) e^{-x}\left(v_{2}(y+\Delta y)-v_{2}(y)\right)+o(\Delta y) .
\end{aligned}
$$

The last expression above implies that

$$
\begin{aligned}
& \left.P\left(\max \left(U_{2}^{0}, U_{3}^{0}\right) \leq x, \max \left(U_{1}(Y), U_{3}(Y)\right) \leq U_{2}(Y), Y \in d y\right) \mid U_{1}^{0}=x\right) \\
& =\exp \left(-e^{-x} \psi_{3}(y)\right) \exp \left(-e^{-x} v_{2}(y)\right) e^{-x} v_{2}(d y) .
\end{aligned}
$$

Thus, using (A.1) and Lemma 1, we obtain

$$
\begin{aligned}
& \left.P\left(J^{0}=1, J=2, Y \in[y, y+\Delta y)\right)=E P\left(\max \left(U_{2}^{0}, U_{3}^{0}\right) \leq U_{1}^{0}, \max \left(U_{1}(Y), U_{3}(Y)\right) \leq U_{2}(Y), Y \in d y\right) \mid U_{1}^{0}\right) \\
& v_{2}(d y) \int_{-\infty}^{\infty} \exp \left(-e^{-x} \psi_{3}(y)\right) \exp \left(-e^{-x} v_{2}(y)\right) e^{-x} \exp \left(-e^{-x} v_{1}^{0}\right) e^{-x} v_{1}^{0} d x
\end{aligned}
$$




$$
=\frac{v_{1}^{0} v_{2}(d y)}{\left\{v_{1}^{0}+v_{2}(y)+\psi_{3}(y)\right\}^{2}}
$$

from which Theorem 1 follows. In the general case with more than three alternatives we have

$$
\begin{aligned}
& P\left(J^{0}=1, J=2, Y \in[y, y+\Delta y)\right) \\
= & P\left(\max _{r \neq 1} U_{r}^{0} \leq x, \max _{r \neq 2} U_{r}(Y) \leq U_{2}(Y), Y \in(y, y+\Delta y) \mid U_{1}^{0}=x\right) \\
= & P\left(\max _{r \neq 1} U_{r}^{0} \leq x, \max _{r \neq 2} U_{r}(y) \leq x, U_{2}(y) \leq x<U_{2}(y+\Delta y) \mid U_{1}^{0}=x\right)+o(\Delta) \\
= & P\left(\max _{r \neq\{1,2\}}\left(U_{r}^{0}, U_{r}(y)\right) \leq x, U_{2}(y) \leq x<U_{2}(y+\Delta y) \mid U_{1}^{0}=x\right)+o(\Delta) \\
= & P\left(\max _{r \neq\{1,2\}}\left(\log \psi_{r}(y)+\varepsilon_{r}\right) \leq x, U_{2}(y) \leq x<U_{2}(y+\Delta y) \mid U_{1}^{0}=x\right)+o(\Delta) \\
= & P\left(\max _{r \neq\{1,2\}}\left(\log \psi_{r}(y)+\varepsilon_{r}\right) \leq x\right) P\left(U_{2}(y) \leq x<U_{2}(y+\Delta y) \mid U_{1}^{0}=x\right)+o(\Delta) .
\end{aligned}
$$

The rest of the proof in the general case is similar to the ternary case.

Q.E.D.

\section{Proof of Corollary 1:}

The result in (2.4) follows immediately from (2.3) because we have

$$
P^{H}(j, k)=\int_{y_{k}}^{y_{j}} \varphi(j, k, d y) .
$$

Consider the result in (2.5). For this to happen it must be the case that $U_{j}^{0}=U_{j}(Y)$, which implies that $Y=y_{j}$. Furthermore, one must have

$$
U_{j}^{0} \geq \max _{r \neq j}\left(U_{r}^{0}, U_{r}\left(y_{j}\right)\right)=\max _{r \neq j}\left(\log \psi_{r}\left(y_{j}\right)+\varepsilon_{j}\right) .
$$

The corresponding probability is equal to

$$
P^{H}(j, j)=\frac{v_{j}^{0}}{v_{j}^{0}+\sum_{r=1, r \neq j}^{m} \psi_{r}\left(y_{j}\right)}=\frac{v_{j}^{0}}{\sum_{r=1}^{m} \psi_{r}\left(y_{j}\right)} .
$$

The last equality follows from the fact that $v_{j}^{0}=v_{j}\left(y_{j}\right)$.

Q.E.D.

\section{Proof of Corollary 2:}

Note that when $\left\{v_{k}(y)\right\}$ is continuously differentiable we have

$$
\sum_{k} 1\left\{y>y_{k}\right\} v_{k}^{\prime}(y)=\sum_{k} \psi_{k}^{\prime}(y)
$$

because $\psi_{k}(y)$ does not depend on y when $y \leq y_{k}$. Therefore, it follows that

$$
\sum_{j, k} 1\left\{y_{j} \geq y \geq y_{k}\right\} v_{j}^{0} v_{k}^{\prime}(y)=\sum_{j} 1\left\{y_{j}>y\right\} v_{j}^{0} \sum_{k} 1\left\{y>y_{k}\right\} v_{k}^{\prime}(y)=\sum_{j} 1\left\{y_{j}>y\right\} v_{j}^{0} \sum_{k} \psi_{k}(y) .
$$


Hence

$$
\sum_{j, k} 1\left\{y_{j} \geq y \geq y_{k}\right\} \partial \varphi(j, k, y) / \partial=\frac{\sum_{j, k} 1\left\{y_{j} \geq y \geq y_{k}\right\} v_{j}^{0} v_{k}^{\prime}(y)}{\left\{\sum_{r=1}^{m} \psi_{r}(y)\right\}^{2}}=\frac{\sum_{j} 1\left\{y_{j} \geq y\right\} v_{j}^{0} \sum_{r=1}^{m} v_{k}^{\prime}(y)}{\left\{\sum_{r=1}^{m} \psi_{r}(y)\right\}^{2}}
$$

Q.E.D.

\section{Proof of Corollary 3:}

Recall that as in the proof above we have

$$
\sum_{k} 1\left\{y>y_{k}\right\} v_{k}(d y)=\sum_{k} \psi_{k}(d y)
$$

because $\psi_{k}(y)$ does not depend on y when $y \leq y_{k}$. Hence (2.2) implies that when $y \leq y_{j}$ then

$$
P\left(J^{0}=j, Y \in[y, y+d y)\right)=\sum_{k} 1\left\{y>y_{k}\right\} \varphi(j, k, d y)=\frac{v_{j}^{0} \sum_{k} 1\left\{y>y_{k}\right\} v_{k}(d y)}{\left\{\sum_{r=1}^{m} \psi_{r}(y)\right\}^{2}}=\frac{v_{j}^{0} \sum_{k} \psi_{k}(d y)}{\left\{\sum_{r=1}^{m} \psi_{r}(y)\right\}^{2}} .
$$

By integrating the last expression with respect to $y$, the result of Corollary 3 follows.

Q.E.D.

Derivation of the distribution of $\max _{z \in B(h)} \varepsilon(z)$

By assumption

$$
\begin{aligned}
& P\left(\max _{z \in B(h)} \varepsilon(z)-\log (\theta g(h)) \leq x\right)=\prod_{z \in B(h)} P(\varepsilon(z) \leq x+\log (\theta g(h)))=\exp \left\{-\sum_{z \in B(h)} \exp (-x-\log (\theta g(h)))\right\} \\
& =\exp (-\theta g(h) \exp (-x-\log (\theta g(h)))\}=\exp \left(-e^{-x}\right) .
\end{aligned}
$$

The last equation follows from the fact that $\theta g(h)$ is the number of job alternatives in $B(h)$.

Q.E.D.

\section{Appendix B}

\section{The two-sector discrete labor supply model}

This section outlines the two-sector job choice model for married females. Here it is assumed that the female takes her husband's income as given. Let $w_{k}$ denote the wage the female receives when working in sector $k, k=$ 1,2 , and let $w=\left(w_{1}, w_{2}\right)$. The budget constraint when working in sector $k, k=1,2$, is given by

$$
C_{k}=f\left(h w_{k}, I\right) \equiv h w_{k}-T\left(h w_{k}\right)+I,
$$

where $T$ is the tax function, $h$ is hours of work and $I$ is the sum of three income components. These three incomes are the after-tax wage income of the husband, the capital income (taxed at 28 percent) of the household, 
and child allowances, which vary with the number of children up to the age of 18 . Child allowances are not taxed. All details of the tax structure $T($.$) are taken into account in the estimation and simulation of the model.$ Let $\varphi_{k}(h)$ be the uncompensated probability of choosing a job in sector $k$ with hours of work $h$ (for a utility maximizing agent), and let $D$ be the set of feasible hours (assumed to be the same across sectors). As in Section 3, it is demonstrated by Dagsvik and Strøm (2006) that

$$
\varphi_{k}(h)=\frac{v\left(f\left(h w_{k}, I\right), h\right) g_{k}(h) \theta_{k}}{v(f(0, y), 0)+\sum_{r=1}^{2} \sum_{x>0, x \in D} v\left(f\left(x w_{r}, I\right), x\right) g_{r}(x) \theta_{r}}
$$

for $h>0, k=1,2$, where $g_{k}(h)$ denotes the fraction of jobs with hours of work that are available in sector $k$ (available to the agent). The term $\theta_{k}$ is a measure of the total number of jobs available to the female in sector $k, k$ $=1,2$. For $h=0, \varphi(0)$ is obtained from (B.1) by replacing the numerator with $v(f(0, y), 0)$.

The deterministic part of the utility function is specified as a Box-Cox transformation of consumption and leisure:

$$
\begin{aligned}
& \log v(C, h)=\alpha_{2}\left(\frac{\left[10^{-4}\left(C-C_{0}\right)\right]^{\alpha_{1}}-1}{\alpha_{1}}\right)+\alpha_{9}\left(\frac{\left[10^{-4}\left(C-C_{0}\right)\right]^{\alpha_{1}}-1}{\alpha_{1}}\right)\left(\frac{(1-h / 3640)^{\alpha_{3}}-1}{\alpha_{3}}\right) \\
& +\left(\alpha_{4}+\alpha_{5} \log A+\alpha_{6}(\log A)^{2}+\alpha_{7} X_{0,6}+\alpha_{8} X_{7,17}\right)\left(\frac{(1-h / 3640)^{\alpha_{3}}-1}{\alpha_{3}}\right) .
\end{aligned}
$$

Here $C_{0}$ is minimum consumption, $A$ is age, and $X_{06}, X_{7,17}$ are the number of children below 6 and between 7 and 17 respectively. The alpha-s are unknown coefficients. If $\alpha_{1}$ and $\alpha_{3}$ are below 1 , the deterministic part of the utility function is strictly concave. In order to make the paper self-contained, information about data, tax functions, and estimates is appended: see Tables C.1- C.4.

Consider now the calculation of the compensated choice probabilities in the context of a reform of the tax system or a change in wages. Here we shall assume that the opportunity measures $\theta_{k} g_{k}(h)$ remain unaffected by the reform. Let $f^{0}$ and $f$ represent the initial and ex-post tax system and $w_{k}^{0}$ and $w_{k}$ the initial and ex-post wage in sector $k$. Let $y_{k}(h)$ be defined by $v\left(f^{0}\left(h w_{k}^{0}, I\right), h\right)=v\left(f\left(h w, y_{k}(h)\right), h\right)$, for positive $h$ and $k$, and let $y_{0}(0)=y(0)$, for $h=k=0$. The function $y_{k}(h)$ is the ex-post non-labor income that makes the ex-ante deterministic part of utility equal to the corresponding ex-post part. Since the function $v$ and the opportunity measures are unaffected by the reform it follows that the equation above is equivalent to

$$
f^{0}\left(h w_{k}^{0}, I\right)=f\left(h w_{k}, y_{k}(h)\right) .
$$


Similarly to the definition in (3.2), let $P^{H}\left(j, h^{0}, k, h\right)$ denote the joint probability of being in sector $j$ working $h^{0}$ hours ex-ante and working $h$ hours in sector $k$ ex post, given that the ex-ante and ex-post maximal utilities are the same. Here $j, k=0,1,2$, where by sector 0 we understand the alternative not working. As in (3.3), it follows from Dagsvik and Karlström (2005) that

$$
P^{H}\left(j, h^{0}, k, h\right)=1\left\{y_{j}\left(h^{0}\right)>y_{k}(h)\right\} \int_{y_{k}(h)}^{y_{j}\left(h^{0}\right)} \frac{g_{j}\left(h^{0}\right) g_{k}(h) \theta_{j} \theta_{k} v\left(f^{0}\left(h^{0} w_{j}^{0}, I\right), h^{0}\right) v\left(f\left(h w_{k}, d y\right), h\right)}{K(y)^{2}},
$$

which is valid for positive hours and $k>0, j>0,\left(j, h^{0}\right) \neq(k, h)$. Due to (A.2), it follows that

$$
\begin{aligned}
& K(y)=\max \left(v\left(f^{0}(0, I), 0\right), v(f(0, y), 0)\right) \\
& +\sum_{r=1}^{2} \sum_{x \in D} \max \left(g_{r}(x) \theta_{r} v\left(f^{0}\left(x w_{r}^{0}, I\right), x\right), g_{r}(x) \theta_{r} v\left(f\left(x w_{r}, y\right), x\right)\right)
\end{aligned}
$$

and

$$
v\left(f\left(h w_{k}, d y\right), h\right)=\left(\alpha_{2}+\alpha_{9}\left(\frac{(1-h / 3640)^{\alpha_{3}}-1}{\alpha_{3}}\right)\right)\left(10^{-4}\left(f\left(h w_{k}, y\right)-C_{o}\right)\right)^{\alpha_{1}-1} v\left(f\left(h w_{k}, y\right), h\right) d y .
$$

The cases with not working alternatives we obtain that:

$$
P^{H}\left(j, h^{0}, 0,0\right)=1\left\{y_{j}\left(h^{0}\right)>y_{0}(0)\right\} \int_{y(0)}^{y_{j}\left(h^{0}\right)} \frac{g_{j}\left(h^{0}\right) \theta_{j} v\left(f^{0}\left(h^{0} w_{k}^{0}, I\right), h^{0}\right) v(f(0, d y), 0)}{K(y)^{2}},
$$

$$
P^{H}(0,0, k, h)=1\left\{y_{0}(0)>y_{k}(h)\right\} \int_{y_{k}(h)}^{y(0)} \frac{g_{k}(h) \theta_{k} v\left(f^{0}(0, I), 0\right) v\left(f\left(h w_{k}, d y\right)\right)}{K(y)^{2}},
$$

$$
P^{H}(j, h, j, h)=\frac{g_{j}(h) \theta_{j} v\left(f^{0}\left(h w_{k}^{0}, I\right), h\right)}{K\left(y_{j}(h)\right)},
$$

for positive $h$ and $j$, and

$$
P^{H}(0,0,0,0)=\frac{\left.v\left(f^{0}(0, I), 0\right)\right)}{K(y(0))}
$$

for $j=h=0$.

Let $\varphi_{k}^{H}(h)$ be the probability that the agent chooses $(k, h)$ ex-post, given that utility is the same as before the reform. Then for $h>0$,

$$
\varphi_{k}^{H}(h)=\sum_{j \neq k} \sum_{x \in D \backslash\{h\}} P^{H}(j, x, k, h)+\sum_{x \in D \backslash\{h\}} P^{H}(k, x, k, h)+\sum_{j \neq k} P^{H}(j, h, k, h)+P^{H}(k, h, k, h),
$$

for $h, k>0$, and

$$
\varphi^{H}(0)=\sum_{x \in D} \sum_{j>0} P^{H}(j, x, 0,0)+P^{H}(0,0,0,0) .
$$

The compensated and the relative change for all $(h, k)$ is given by 
(B.13) $\varphi_{k}^{H}(h)-\varphi_{k}^{0}(h)$ and $\quad \frac{\varphi_{k}^{H}(h)-\varphi_{k}^{0}(h)}{\varphi_{k}^{0}(h)}$. 


\section{Appendix C}

\section{Data, tax functions, and estimates}

Data on the labor supply of married women in Norway used in this study consist of a merged sample of the "Survey of Income and Wealth, 1994" and the "Level of living conditions, 1995" (Statistics Norway, 1994 and 1995 respectively). Data cover married couples as well as cohabiting couples with common children. The ages of the spouses range from 25 to 64 . None of the spouses is self-employed and none of them is on disability or other types of benefits. A person is classified as a wage worker if their income from wage work is higher than their income from self-employment. All taxes paid are observed and in the assessment of disposable income, at hours not observed, all details of the tax system are accounted for. Hours of work are calculated as the sum of hours of the main job as well as those of any subsidiary jobs. A large majority of the women have only one job.

Wage rates above NOK 350 or below NOK $40^{6}$ are not utilized when estimating the wage equations. The wage rates are computed as the ratio of annual wage income to hours worked. When computing annual wage income, we take into account the fact that some women have multiple jobs. The size of the sample used in estimating the labor supply model is 810 . Descriptions of variables and summary statistics are given in Table C.1.

Table C.1. Descriptive statistics, number of observations $=810$ (values in NOK, 1994)

\begin{tabular}{lllll}
\hline Variable & Mean & Std Dev. & Min. & Max. \\
\hline Number of children (age 0-2) & 0.23 & 0.45 & 0.00 & 2.00 \\
Number of children (age 0-6) & 0.54 & 0.77 & 0.00 & 3.00 \\
Number of children (age 3-6) & 0.30 & 0.56 & 0.00 & 3.00 \\
Number of children (age 7-17) & 0.66 & 0.85 & 0.00 & 4.00 \\
Age in year (men) & 42.80 & 9.17 & 25.00 & 66.00 \\
Education in year (men) & 12.05 & 2.49 & 9.00 & 19.00 \\
Age in year (women) & 40.07 & 9.04 & 25.00 & 64.00 \\
Education in year (women) & 11.61 & 2.15 & 9.00 & 17.00 \\
Sector (1 = Public, 2 = Private) & 1.34 & 0.61 & 0.00 & 2.00 \\
Work experience (woman age - & 22.45 & 9.63 & 2.00 & 49.00 \\
woman education in years) & & & & \\
Capital income (child allowances & 32306.71 & 42378.48 & 0.00 & 568403.00 \\
included) & 13094.37 & 12154.01 & 0.00 & 60084.00 \\
Child allowances & 149751.97 & 83060.53 & 0.00 & 581693.00 \\
Women wage income per year & 274372.89 & 106239.67 & 17312.00 & 1184861.00 \\
Men wage income per year & 89.36 & 12.09 & 64.88 & 132.34 \\
Woman hourly wage in public sector & 109.77 & 13.68 & 80.14 & 156.44 \\
Woman hourly wage in private sector & 109 & & &
\end{tabular}

\footnotetext{
${ }^{6}$ As of June 2013, 1 USD $=$ NOK 5.80.
} 
Table C.2. Estimates of the model parameters

Variables

Parameters

Estimates

t-values

\section{Preferences}

Consumption

Exponent

$\begin{array}{lll}\alpha_{1} & 0.64 & 7.6 \\ \alpha_{2} & 1.77 & 4.2 \\ & 60000 & \end{array}$

Subsistence level $\mathrm{C}_{0}$ in NOK per year

60000

Leisure

Exponent

$\alpha_{3}$

$-0.53$

$-2.1$

Constant

$\alpha_{4}$

111.66

3.2

Log age

$\alpha_{5}$

$-63.61$

$-3.2$

$(\text { log age })^{2}$

$\alpha_{6}$

9.2

3.3

\# children 0-6

$\alpha_{7}$

1.27

4.0

\# children 7-17

$\alpha_{8}$

0.97

4.1

Consumption and Leisure, interaction

Subsistence level of leisure in hours per year

$\alpha_{9}$

$-0.12$

The parameters $\theta_{1}$ and $\theta_{2} ; \log \theta_{j}=f_{j 1}+f_{j 2} S$

Constant, public sector (sector 1 )

Constant, private sector (sector 2)

Education, public sector (sector 1)

Education, private sector (sector 2)

5120

$\begin{array}{ccc}\mathrm{f}_{11} & -4.2 & -4.7 \\ \mathrm{f}_{21} & 1.14 & 1.0 \\ \mathrm{f}_{12} & 0.22 & 2.9 \\ \mathrm{f}_{22} & -0.34 & -3.3\end{array}$

Opportunity density of offered hours, $g_{k 2}(h), k=1,2$

Full-time peak, public sector (sector 1$)^{*}$

$\begin{array}{lll}\log \left(\mathrm{g}_{12}\left(\mathrm{~h}_{\text {Full }}\right) / \mathrm{g}_{12}\left(\mathrm{~h}_{0}\right)\right) & 1.58 & 11.8 \\ \log \left(\mathrm{g}_{22}\left(\mathrm{~h}_{\text {Full }}\right) / \mathrm{g}_{22}\left(\mathrm{~h}_{0}\right)\right) & 1.06 & 7.4 \\ \log \left(\mathrm{g}_{12}\left(\mathrm{~h}_{\text {Par }}\right) / \mathrm{g}_{12}\left(\mathrm{~h}_{0}\right)\right) & 0.68 & 4.4 \\ \log \left(\mathrm{g}_{22}\left(\mathrm{~h}_{\text {Par }}\right) / \mathrm{g}_{22}\left(\mathrm{~h}_{0}\right)\right) & 0.8 & 5.2 \\ & 824 & \end{array}$

Full-time peak, private sector (sector 2)

Part-time peak, public Sector

Part-time peak, private Sector

\# observations

$-1760.9$

Log likelihood

${ }^{*}$ The notation $\mathrm{h}_{0}$ refers to an arbitrary level of hours of work different from full-time and part-time hours.

The deterministic part of the utility function, i.e. the numerator in the choice probabilities, given participation, is quasi-concave for all individuals in the sample. 
Table C.3. Tax function in 1994 for a married non-working woman whose husband is working, 1994

\begin{tabular}{ll}
\hline Male income, $\mathrm{Y}_{\text {male }}$ & Tax T \\
\hline $0-41,907$ & 0 \\
$41,907-140,500$ & $0.302 \mathrm{Y}_{\text {male }}-12656$ \\
$140,500-252,000$ & $0.358 \mathrm{Y}_{\text {male }}-20524$ \\
$252,000-263,000$ & $0.453 \mathrm{Y}_{\text {male }}-44464$ \\
$263,000-$ & $0.495 \mathrm{Y}_{\text {male }}-55510$
\end{tabular}

Table C. 4. Tax function in 1994 for a married working woman or man, NOK 1994

\begin{tabular}{ll}
\hline Wage income, $\mathrm{Y}$ & Tax T \\
\hline $0-20,954$ & 0 \\
$20,954-140,500$ & $0.302 \mathrm{Y}-6328$ \\
$140,500-208,000$ & $0.358 \mathrm{Y}-14196$ \\
$208,000-236,500$ & $0.453 \mathrm{Y}-33956$ \\
$236,500-$ & $0.495 \mathrm{Y}-43889$ \\
\hline
\end{tabular}




\section{Appendix D}

\section{Elasticities}

\section{Table D.1. Married woman aged 30, no children}

Wage NOK 70

\begin{tabular}{llllllllllll}
\hline Income & Elasticity & \multicolumn{4}{l}{ Probability of working } & \multicolumn{3}{c}{ Conditional mean hours } & \multicolumn{3}{c}{ Unconditional mean hours } \\
\hline \multirow{3}{*}{50,000} & & All & Public & Private & All & Public & Private & All & Public & Private \\
\cline { 2 - 11 } & Uncompensated & 0.000 & 0.007 & -0.043 & 0.163 & 0.152 & 0.222 & 0.163 & 0.160 & 0.178 \\
& Compensated & 0.131 & 0.135 & 0.111 & 0.186 & 0.174 & 0.254 & 0.318 & 0.310 & 0.365 \\
\multirow{2}{*}{100,000} & Income & 0.000 & -0.007 & 0.040 & -0.060 & -0.057 & -0.081 & -0.060 & -0.064 & -0.041 \\
& Uncompensated & 0.029 & 0.057 & -0.089 & 0.269 & 0.254 & 0.352 & 0.299 & 0.306 & 0.259 \\
& Compensated & 0.183 & 0.205 & 0.061 & 0.254 & 0.239 & 0.335 & 0.438 & 0.445 & 0.397 \\
& Income & -0.022 & -0.031 & 0.028 & -0.080 & -0.076 & -0.101 & -0.102 & -0.107 & -0.073 \\
200,000 & Uncompensated & 0.119 & 0.149 & -0.038 & 0.355 & 0.338 & 0.441 & 0.479 & 0.493 & 0.401 \\
& Compensated & 0.276 & 0.324 & 0.015 & 0.319 & 0.305 & 0.389 & 0.596 & 0.629 & 0.404 \\
& Income & -0.046 & -0.054 & -0.009 & -0.062 & -0.060 & -0.074 & -0.109 & -0.114 & -0.083
\end{tabular}

Wage NOK 200

\begin{tabular}{lllllllllll}
\hline Income & Elasticity & \multicolumn{4}{l}{ Probability of working } & \multicolumn{3}{c}{ Conditional mean hours } & \multicolumn{3}{c}{ Unconditional mean hours } \\
\hline \multirow{3}{*}{50,000} & Uncompensated & All & Public & Private & All & Public & Private & All & Public & Private \\
\cline { 3 - 12 } & 0.000 & -0.046 & 0.245 & 0.192 & 0.190 & 0.194 & 0.192 & 0.142 & 0.445 \\
& Compensated & 0.295 & 0.237 & 0.588 & 0.224 & 0.223 & 0.222 & 0.519 & 0.461 & 0.810 \\
\multirow{2}{*}{100,000} & Income & 0.000 & 0.001 & -0.007 & -0.008 & -0.008 & -0.009 & -0.008 & -0.007 & -0.017 \\
& Uncompensated & 0.000 & -0.043 & 0.231 & 0.207 & 0.203 & 0.220 & 0.207 & 0.158 & 0.457 \\
& Compensated & 0.272 & 0.219 & 0.546 & 0.221 & 0.219 & 0.225 & 0.493 & 0.438 & 0.771 \\
& Income & 0.000 & 0.001 & -0.007 & -0.012 & -0.011 & -0.014 & -0.012 & -0.010 & -0.021 \\
200,000 & Uncompensated & 0.000 & -0.039 & 0.202 & 0.216 & 0.211 & 0.239 & 0.216 & 0.172 & 0.453 \\
& Compensated & 0.240 & 0.194 & 0.481 & 0.215 & 0.212 & 0.227 & 0.456 & 0.406 & 0.709 \\
& Income & 0.000 & 0.000 & 0.000 & -0.010 & -0.010 & -0.013 & -0.010 & -0.010 & -0.013
\end{tabular}


Wage NOK 300

\begin{tabular}{lllllllllll}
\hline Income & Elasticity & \multicolumn{3}{l}{ Probability of working } & \multicolumn{3}{c}{ Conditional mean hours } & \multicolumn{3}{c}{ Unconditional mean hours } \\
\hline \multirow{3}{*}{50,000} & Uncompensated & All & Public & Private & All & Public & Private & All & Public & Private \\
\cline { 3 - 12 } & 0.000 & -0.049 & 0.229 & 0.178 & 0.184 & 0.147 & 0.178 & 0.134 & 0.380 \\
& Compensated & 0.347 & 0.297 & 0.574 & 0.169 & 0.175 & 0.138 & 0.516 & 0.472 & 0.713 \\
\multirow{2}{*}{100,000} & Income & 0.000 & 0.001 & -0.006 & -0.004 & -0.005 & -0.004 & -0.004 & -0.003 & -0.010 \\
& Uncompensated & 0.000 & -0.051 & 0.240 & 0.186 & 0.192 & 0.155 & 0.186 & 0.140 & 0.399 \\
& Compensated & 0.338 & 0.286 & 0.570 & 0.173 & 0.179 & 0.142 & 0.511 & 0.465 & 0.713 \\
& Income & 0.000 & 0.002 & -0.009 & -0.007 & -0.007 & -0.006 & -0.007 & -0.005 & -0.015 \\
200,000 & Uncompensated & 0.000 & -0.052 & 0.249 & 0.195 & 0.200 & 0.165 & 0.195 & 0.147 & 0.418 \\
& Compensated & 0.315 & 0.263 & 0.549 & 0.175 & 0.181 & 0.146 & 0.490 & 0.444 & 0.695 \\
& Income & 0.000 & 0.001 & -0.008 & -0.007 & -0.007 & -0.006 & -0.007 & -0.005 & -0.015
\end{tabular}

Table D.2. Woman aged 30, two children

Wage NOK 70

\begin{tabular}{lllllllllll}
\hline Income & Elasticity & \multicolumn{3}{c}{ Probability of working } & \multicolumn{3}{c}{ Conditional mean hours } & \multicolumn{3}{c}{ Unconditional mean hours } \\
\hline \multirow{3}{*}{50,000} & & All & Public & Private & All & Public & Private & All & Public & Private \\
\cline { 3 - 11 } & Uncompensated & 0.047 & 0.096 & -0.190 & 0.462 & 0.451 & 0.498 & 0.511 & 0.551 & 0.299 \\
& Compensated & 0.327 & 0.394 & -0.012 & 0.494 & 0.481 & 0.536 & 0.821 & 0.876 & 0.523 \\
\multirow{2}{*}{100,000} & Income & -0.046 & -0.059 & 0.014 & -0.131 & -0.128 & -0.137 & -0.177 & -0.187 & -0.122 \\
& Uncompensated & 0.254 & 0.304 & 0.021 & 0.593 & 0.589 & 0.595 & 0.862 & 0.911 & 0.618 \\
& Compensated & 0.581 & 0.704 & -0.017 & 0.667 & 0.675 & 0.569 & 1.249 & 1.379 & 0.551 \\
\multirow{2}{*}{200,000} & Income & -0.126 & -0.137 & -0.075 & -0.149 & -0.148 & -0.146 & -0.273 & -0.284 & -0.221 \\
& Uncompensated & 0.511 & 0.554 & 0.319 & 0.634 & 0.637 & 0.603 & 1.177 & 1.227 & 0.942 \\
& Compensated & 0.682 & 0.830 & -0.027 & 0.410 & 0.382 & 0.508 & 1.093 & 1.212 & 0.480 \\
& Income & -0.167 & -0.173 & -0.141 & -0.111 & -0.112 & -0.105 & -0.277 & -0.283 & -0.246
\end{tabular}

Wage NOK 200

\begin{tabular}{lllllllllll}
\hline Income & Elasticity & \multicolumn{3}{l}{ Probability of working } & \multicolumn{3}{c}{ Conditional mean hours } & \multicolumn{3}{c}{ Unconditional mean hours } \\
\hline \multirow{2}{*}{50,000} & Uncompensated & All & Public & Private & All & Public & Private & All & Public & Private \\
\cline { 3 - 11 } & 0.000 & 0.001 & -0.006 & 0.201 & 0.188 & 0.277 & 0.201 & 0.189 & 0.271 \\
& Compensated & 0.246 & 0.232 & 0.325 & 0.212 & 0.200 & 0.287 & 0.458 & 0.432 & 0.613 \\
\multirow{2}{*}{100,000} & Income & 0.000 & -0.001 & 0.009 & -0.014 & -0.013 & -0.020 & -0.014 & -0.015 & -0.011 \\
& Uncompensated & 0.000 & 0.008 & -0.048 & 0.231 & 0.216 & 0.319 & 0.231 & 0.222 & 0.270 \\
& Compensated & 0.247 & 0.241 & 0.281 & 0.227 & 0.213 & 0.310 & 0.475 & 0.455 & 0.591 \\
& Income & 0.000 & -0.003 & 0.018 & -0.025 & -0.020 & -0.034 & -0.025 & -0.027 & -0.016 \\
200,000 & Uncompensated & 0.001 & 0.019 & -0.101 & 0.278 & 0.261 & 0.381 & 0.280 & 0.281 & 0.276 \\
& Compensated & 0.249 & 0.253 & 0.221 & 0.254 & 0.238 & 0.347 & 0.503 & 0.492 & 0.568 \\
& Income & 0.000 & -0.006 & 0.027 & -0.035 & -0.032 & -0.046 & -0.035 & -0.038 & -0.019
\end{tabular}


Wage NOK 300

\begin{tabular}{lllllllllll}
\hline Income & Elasticity & \multicolumn{3}{l}{ Probability of working } & \multicolumn{3}{c}{ Conditional mean hours } & \multicolumn{3}{c}{ Unconditional mean hours } \\
\hline \multirow{3}{*}{50,000} & & All & Public & Private & All & Public & Private & All & Public & Private \\
\cline { 2 - 11 } & Uncompensated & 0.000 & -0.053 & 0.296 & 0.229 & 0.223 & 0.252 & 0.229 & 0.169 & 0.556 \\
& Compensated & 0.440 & 0.367 & 0.826 & 0.273 & 0.270 & 0.284 & 0.714 & 0.637 & 1.110 \\
& Income & 0.000 & 0.001 & -0.005 & -0.006 & -0.006 & -0.007 & -0.006 & -0.005 & -0.013 \\
100,000 & Uncompensated & 0.000 & -0.050 & 0.282 & 0.234 & 0.228 & 0.264 & 0.234 & 0.176 & 0.553 \\
& Compensated & 0.413 & 0.345 & 0.778 & 0.268 & 0.263 & 0.284 & 0.681 & 0.608 & 1.063 \\
& Income & 0.000 & 0.001 & -0.006 & -0.010 & -0.009 & -0.012 & -0.010 & -0.008 & -0.019 \\
200,000 & Uncompensated & 0.000 & -0.045 & 0.253 & 0.244 & 0.235 & 0.284 & 0.244 & 0.189 & 0.544 \\
& Compensated & 0.375 & 0.315 & 0.702 & 0.260 & 0.253 & 0.285 & 0.635 & 0.568 & 0.988 \\
& Income & 0.000 & 0.000 & -0.002 & -0.013 & -0.012 & -0.016 & -0.013 & -0.011 & -0.019
\end{tabular}

Table D.3. Married woman aged 40, no children

Wage NOK 70

\begin{tabular}{lllllllllll}
\hline Income & Elasticity & \multicolumn{3}{l}{ Probability of working } & \multicolumn{3}{c}{ Conditional mean hours } & \multicolumn{3}{c}{ Unconditional mean hours } \\
\hline \multirow{3}{*}{50,000} & & All & Public & Private & All & Public & Private & All & Public & Private \\
\cline { 3 - 11 } & Uncompensated & 0.000 & 0.019 & -0.078 & 0.187 & 0.172 & 0.249 & 0.187 & 0.192 & 0.168 \\
& Compensated & 0.148 & 0.164 & 0.083 & 0.211 & 0.195 & 0.283 & 0.360 & 0.359 & 0.366 \\
\multirow{2}{*}{100,000} & Income & 0.000 & -0.012 & 0.050 & -0.076 & -0.070 & -0.098 & -0.076 & -0.082 & -0.048 \\
& Uncompensated & 0.045 & 0.085 & -0.107 & 0.319 & 0.298 & 0.399 & 0.366 & 0.384 & 0.287 \\
& Compensated & 0.225 & 0.271 & 0.042 & 0.303 & 0.282 & 0.380 & 0.582 & 0.553 & 0.422 \\
& Income & -0.034 & -0.049 & 0.022 & -0.100 & -0.094 & -0.120 & -0.134 & -0.143 & -0.098 \\
200,000 & Uncompensated & 0.177 & 0.226 & -0.004 & 0.417 & 0.395 & 0.490 & 0.601 & 0.631 & 0.486 \\
& Compensated & 0.364 & 0.458 & 0.000 & 0.389 & 0.372 & 0.433 & 0.753 & 0.831 & 0.433 \\
& Income & -0.069 & -0.080 & -0.030 & -0.078 & -0.075 & -0.088 & -0.147 & -0.155 & -0.119
\end{tabular}

Wage NOK 200

\begin{tabular}{lllllllllll}
\hline Income & Elasticity & \multicolumn{3}{l}{ Probability of working } & \multicolumn{3}{c}{ Conditional mean hours } & \multicolumn{3}{c}{ Unconditional mean hours } \\
\hline \multirow{2}{*}{50,000} & Uncompensated & All & Public & Private & All & Public & Private & All & Public & Private \\
\cline { 3 - 12 } & 0.000 & -0.053 & 0.209 & 0.199 & 0.192 & $0-218$ & 0.199 & 0.138 & 0.432 \\
& Compensated & 0.291 & 0.220 & 0.563 & 0.229 & 0.224 & 0.240 & 0.521 & 0.445 & 0.804 \\
\multirow{2}{*}{100,000} & Income & 0.000 & 0.001 & -0.005 & -0.009 & -0.009 & -0.011 & -0.009 & -0.007 & -0.016 \\
& Uncompensated & 0.000 & -0.049 & 0.193 & 0.209 & 0.200 & 0.236 & 0.209 & 0.150 & 0.434 \\
& Compensated & 0.270 & 0.205 & 0.517 & 0.226 & 0.220 & 0.244 & 0.498 & 0.426 & 0.762 \\
\multirow{2}{*}{200,000} & Income & 0.000 & 0.001 & -0.004 & -0.013 & -0.013 & -0.016 & -0.013 & -0.011 & -0.021 \\
& Uncompensated & 0.000 & -0.041 & 0.165 & 0.223 & 0.212 & 0.260 & 0.223 & 0.170 & 0.430 \\
& Compensated & 0.241 & 0.187 & 0.450 & 223 & 0.214 & 0.249 & 0.464 & 0.402 & 0.699 \\
& Income & 0.000 & 0.000 & 0.003 & -0.014 & -0.013 & -0.018 & -0.014 & -0.013 & -0.014
\end{tabular}


Wage NOK 300

\begin{tabular}{lllllllllll}
\hline Income & Elasticity & \multicolumn{3}{c}{ Probability of working } & \multicolumn{3}{c}{ Conditional mean hours } & \multicolumn{3}{c}{ Unconditional mean hours } \\
\hline \multirow{3}{*}{50,000} & & All & Public & Private & All & Public & Private & All & Public & Private \\
\cline { 2 - 11 } & Uncompensated & 0.000 & -0.070 & 0.258 & 0.200 & 0.207 & 0.172 & 0.200 & 0.138 & 0.427 \\
& Compensated & 0.393 & 0.315 & 0.650 & 0.198 & 0.206 & 0.167 & 0.591 & 0.521 & 0.817 \\
\multirow{2}{*}{100,000} & Income & 0.000 & 0.002 & -0.007 & -0.005 & -0.005 & -0.004 & -0.005 & -0.003 & -0.011 \\
& Uncompensated & 0.000 & -0.074 & 0.259 & 0.208 & 0.214 & 0.181 & 0.208 & 0.138 & 0.446 \\
& Compensated & 0.379 & 0.301 & 0.640 & 0.201 & 0.208 & 0.171 & 0.581 & 0.510 & 0.812 \\
& Income & 0.000 & 0.002 & -0.010 & -0.008 & -0.008 & -0.007 & -0.008 & -0.005 & -0.017 \\
200,000 & Uncompensated & 0.000 & -0.075 & 0.265 & 0.217 & 0.222 & 0.193 & 0.217 & 0.145 & 0.463 \\
& Compensated & 0.351 & 0.276 & 0.610 & 0.202 & 0.209 & 0.175 & 0.554 & 0.483 & 0.786 \\
& Income & 0.000 & 0.002 & -0.009 & -0.008 & -0.008 & -0.007 & -0.008 & -0.005 & -0.016
\end{tabular}

Table D.4. Married woman aged 40, two children

Wage NOK 70

\begin{tabular}{lllllllllll}
\hline Income & Elasticity & \multicolumn{3}{l}{ Probability of working } & \multicolumn{3}{c}{ Conditional mean hours } & \multicolumn{3}{c}{ Unconditional mean hours } \\
\hline \multirow{3}{*}{50,000} & & All & Public & Private & All & Public & Private & All & Public & Private \\
\cline { 2 - 11 } & Uncompensated & 0.065 & 0.131 & -0.153 & 0.508 & 0.500 & 0.521 & 0.578 & 0.638 & 0.360 \\
& Compensated & 0.371 & 0.474 & 0.011 & 0.566 & 0.557 & 0.571 & 0.938 & 1.031 & 0.582 \\
& Income & -0.065 & -0.082 & -0.010 & -0.145 & -0.143 & -0.146 & -0.210 & -0.224 & -0.156 \\
100,000 & Uncompensated & 0.331 & 0.393 & 0.130 & 0.629 & 0.631 & 0.605 & 0.981 & 1.049 & 0.744 \\
& Compensated & 0.714 & 0.920 & 0.006 & 0.784 & 0.820 & 0.576 & 1.498 & 1.740 & 0.582 \\
& Income & -0.163 & -0.176 & -0.122 & -0.158 & -0.160 & -0.151 & -0.320 & -0.334 & -0.271 \\
200,000 & Uncompensated & 0.620 & 0.670 & 0.465 & 0.649 & 0.660 & 0.599 & 1.309 & 1.374 & 1.093 \\
& Compensated & 0.821 & 1.063 & -0.008 & 0.412 & 0.376 & 0.487 & 1.233 & 1.440 & 0.478 \\
& Income & -0.203 & -0.209 & -0.183 & -0.116 & -0.118 & -0.108 & -0.317 & -0.325 & -0.290
\end{tabular}

Wage NOK 200

\begin{tabular}{lllllllllll}
\hline Income & Elasticity & \multicolumn{3}{c}{ Probability of working } & \multicolumn{3}{c}{ Conditional mean hours } & \multicolumn{3}{c}{ Unconditional mean hours } \\
\hline \multirow{2}{*}{50,000} & Uncompensated & All & Public & Private & All & Public & Private & All & Public & Private \\
\cline { 3 - 11 } & 0.000 & 0.014 & -0.062 & 0.218 & 0.199 & 0.297 & 0.218 & 0.214 & 0.233 \\
& Compensated & 0.257 & 0.253 & 0.273 & 0.223 & 0.204 & 0.301 & 0.480 & 0.458 & 0.575 \\
& Income & 0.000 & -0.003 & 0.013 & -0.018 & -0.016 & -0.024 & -0.018 & -0.019 & -0.011 \\
100,000 & Uncompensated & 0.000 & 0.026 & -0.105 & 0.257 & 0.235 & 0.348 & 0.258 & 0.265 & 0.239 \\
& Compensated & 0.265 & 0.272 & 0.234 & 0.245 & 0.225 & 0.332 & 0.511 & 0.497 & 0.567 \\
& Income & 0.000 & -0.005 & 0.023 & -0.031 & -0.028 & -0.041 & -0.031 & -0.034 & -0.018 \\
200,000 & Uncompensated & 0.002 & 0.042 & -0.156 & 0.316 & 0.291 & 0.419 & 0.319 & 0.335 & 0.255 \\
& Compensated & 0.273 & 0.295 & 0.181 & 0.284 & 0.261 & 0.380 & 0.557 & 0.557 & 0.561 \\
& Income & -0.001 & -0.009 & 0.032 & -0.044 & -0.040 & -0.056 & -0.045 & -0.050 & -0.024
\end{tabular}


Wage NOK 300

\begin{tabular}{lllllllllll}
\hline Income & Elasticity & \multicolumn{4}{l}{ Probability of working } & \multicolumn{3}{c}{ Conditional mean hours } & \multicolumn{3}{c}{ Unconditional mean hours } \\
\hline \multirow{3}{*}{50,000} & Uncompensated & All & Public & Private & All & Public & Private & All & Public & Private \\
\cline { 3 - 11 } & 0.000 & -0.059 & 0.244 & 0.221 & 0.211 & 0.255 & 0.221 & 0.149 & 0.506 \\
& Compensated & 0.419 & 0.331 & 0.765 & 0.267 & 0.259 & 0.292 & 0.687 & 0.590 & 1.057 \\
\multirow{2}{*}{100,000} & Income & 0.000 & 0.000 & -0.003 & -0.006 & -0.006 & -0.008 & -0.006 & -0.005 & -0.012 \\
& Uncompensated & 0.000 & -0.054 & 0.225 & 0.228 & 0.216 & 0.269 & 0.228 & 0.160 & 0.501 \\
& Compensated & 0.395 & 0.315 & 0.715 & 0.261 & 0.252 & 0.292 & 0.657 & 0.567 & 1.008 \\
& Income & 0.000 & 0.000 & -0.003 & -0.011 & -0.010 & -0.014 & -0.011 & -0.009 & -0.018 \\
200,000 & Uncompensated & 0.000 & -0.046 & 0.190 & 0.243 & 0.228 & 0.295 & 0.243 & 0.180 & 0.491 \\
& Compensated & 0.363 & 0.294 & 0.640 & 0.255 & 0.244 & 0.295 & 0.619 & 0.538 & 0.935 \\
& Income & 0.000 & 0.000 & 0.001 & -0.015 & -0.014 & -0.020 & -0.015 & -0.014 & -0.018
\end{tabular}

\section{Appendix E}

Uncompensated probabilities, conditional, and unconditional mean hours

Table E.1 Married woman aged 30, no children

Wage NOK 70

\begin{tabular}{llllllllll}
\hline Income & \multicolumn{3}{l}{ Probability of working } & \multicolumn{3}{c}{ Conditional mean hours } & \multicolumn{3}{c}{ Unconditional mean hours } \\
\hline \multirow{2}{*}{50,000} & All & Public & Private & All & Public & Private & All & Public & Private \\
\cline { 2 - 10 } 100,000 & 0.9900 & 0.8504 & 0.1496 & 1907 & 1912 & 1878 & 1907 & 1626 & 281 \\
200,000 & 0.9691 & 0.8140 & 0.1551 & 1711 & 1725 & 1637 & 1658 & 1404 & 254
\end{tabular}

Wage NOK 200

\begin{tabular}{llllllllll}
\hline Income & \multicolumn{3}{l}{ Probability of working } & \multicolumn{3}{c}{ Conditional mean hours } & \multicolumn{3}{c}{ Unconditional mean hours } \\
\hline \multirow{2}{*}{50,000} & All & Public & Private & All & Public & Private & All & Public & Private \\
\cline { 2 - 9 } 100,000 & 1.0000 & 0.8410 & 0.1590 & 2185 & 2176 & 2230 & 2185 & 1830 & 355 \\
200,000 & 1.0000 & 0.8419 & 0.1581 & 2168 & 2160 & 2211 & 2168 & 1819 & 350 \\
& 0.8424 & 0.1576 & 2149 & 2142 & 2187 & 2149 & 1804 & 345
\end{tabular}


Wage NOK 300

\begin{tabular}{llllllllll}
\hline Income & \multicolumn{3}{l}{ Probability of working } & \multicolumn{3}{c}{ Conditional mean hours } & \multicolumn{3}{c}{ Unconditional mean hours } \\
\hline \multirow{2}{*}{50,000} & All & Public & Private & All & Public & Private & All & Public & Private \\
\hline 100,000 & 1.0000 & 0.8228 & 0.1772 & 2377 & 2369 & 2415 & 2377 & 1949 & 428 \\
200,000 & 1.0000 & 0.8238 & 0.1762 & 2367 & 2359 & 2406 & 2367 & 1943 & 424 \\
& & & 0.1749 & 2354 & 2346 & 2395 & 2354 & 1935 & 419
\end{tabular}

Table E.2 Married woman aged 30, two children

Wage NOK 70

\begin{tabular}{llllllllll}
\hline Income & \multicolumn{3}{l}{ Probability of working } & \multicolumn{3}{c}{ Conditional mean hours } & \multicolumn{3}{c}{ Unconditional mean hours } \\
\hline & All & Public & Private & All & Public & Private & All & Public & Private \\
\cline { 2 - 9 } 50,000 & 0.9894 & 0.8200 & 0.1693 & 1496 & 1515 & 1403 & 1480 & 1243 & 238 \\
100,000 & 0.9331 & 0.7664 & 0.1667 & 1348 & 1366 & 1261 & 1257 & 1047 & 210 \\
200,000 & 0.8352 & 0.6814 & 0.1537 & 1218 & 1235 & 1144 & 1017 & 842 & 176
\end{tabular}

Wage NOK 200

\begin{tabular}{llllllllll}
\hline Income & \multicolumn{3}{l}{ Probability of working } & \multicolumn{3}{c}{ Conditional mean hours } & \multicolumn{3}{c}{ Unconditional mean hours } \\
\hline & All & Public & Private & All & Public & Private & All & Public & Private \\
\cline { 2 - 9 } 50,000 & 1.0000 & 0.8540 & 0.1460 & 1956 & 1958 & 1945 & 1956 & 1672 & 284 \\
100,000 & 1.0000 & 0.8525 & 0.1474 & 1929 & 1933 & 1907 & 1929 & 1648 & 281 \\
200,000 & 0.9997 & 0.8498 & 0.1499 & 1887 & 1894 & 1851 & 1887 & 1609 & 278
\end{tabular}

Wage NOK 300

\begin{tabular}{llllllllll}
\hline Income & \multicolumn{3}{l}{ Probability of working } & \multicolumn{3}{l}{ Conditional mean hours } & \multicolumn{3}{c}{ Unconditional mean hours } \\
\hline & All & Public & Private & All & Public & Private & All & Public & Private \\
\cline { 2 - 9 } 50,000 & 1.0000 & 0.8470 & 0.1530 & 2132 & 2124 & 2173 & 2132 & 1799 & 332 \\
100,000 & 1.0000 & 0.8477 & 0.1523 & 2119 & 2112 & 2157 & 2119 & 1791 & 329 \\
200,000 & 1.0000 & 0.8483 & 0.1517 & 2101 & 2095 & 2135 & 2101 & 1777 & 324
\end{tabular}

Table E.3. Married woman aged 40, no children

Wage NOK 70

\begin{tabular}{llllllllll}
\hline Income & \multicolumn{3}{c}{ Probability of working } & \multicolumn{3}{c}{ Conditional mean hours } & \multicolumn{3}{c}{ Unconditional mean hours } \\
\hline & All & Public & Private & All & Public & Private & All & Public & Private \\
\cline { 2 - 9 } 50,000 & 1.0000 & 0.8020 & 0.1980 & 1855 & 1865 & 1812 & 1855 & 1496 & 359 \\
100,000 & 0.9898 & 0.7858 & 0.2040 & 1739 & 1756 & 1671 & 1721 & 1380 & 341 \\
200,000 & 0.9529 & 0.7490 & 0.2039 & 1621 & 1643 & 1540 & 1545 & 1231 & 314
\end{tabular}


Wage NOK 200

\begin{tabular}{llllllllll}
\hline Income & \multicolumn{3}{l}{ Probability of working } & \multicolumn{3}{c}{ Conditional mean hours } & \multicolumn{3}{c}{ Unconditional mean hours } \\
\hline \multirow{2}{*}{50,000} & All & Public & Private & All & Public & Private & All & Public & Private \\
\cline { 2 - 9 } 100,000 & 1.0000 & 0.7967 & 0.2033 & 2141 & 2131 & 2179 & 2141 & 1698 & 443 \\
200,000 & 1.0000 & 0.7975 & 0.2025 & 2123 & 2115 & 2157 & 2123 & 1686 & 437 \\
& 1.0000 & 0.7977 & 0.2023 & 2101 & 2094 & 2128 & 2101 & 1670 & 431
\end{tabular}

Wage NOK 300

\begin{tabular}{llllllllll}
\hline Income & \multicolumn{3}{l}{ Probability of working } & \multicolumn{3}{c}{ Conditional mean hours } & \multicolumn{3}{c}{ Unconditional mean hours } \\
\hline \multirow{2}{*}{50,000} & All & Public & Private & All & Public & Private & All & Public & Private \\
\cline { 2 - 9 } 100,000 & 1.0000 & 0.7745 & 0.2255 & 2337 & 2326 & 2378 & 2337 & 1801 & 536 \\
200,000 & 1.0000 & 0.7759 & 0.2241 & 2326 & 2314 & 2367 & 2326 & 1795 & 531 \\
& 1.0000 & 0.7776 & 0.2224 & 2311 & 2299 & 2354 & 2311 & 1788 & 524
\end{tabular}

Table E.4. Married woman aged 40, two children

Wage NOK 70

\begin{tabular}{llllllllll}
\hline Income & \multicolumn{3}{l}{ Probability of working } & \multicolumn{3}{c}{ Conditional mean hours } & \multicolumn{3}{c}{ Unconditional mean hours } \\
\hline \multirow{2}{*}{50,000} & All & Public & Private & All & Public & Private & All & Public & Private \\
\cline { 2 - 10 } 100,000 & 0.9848 & 0.7594 & 0.2254 & 1416 & 1440 & 1332 & 1394 & 1094 & 300 \\
200,000 & 0.9099 & 0.6937 & 0.2161 & 1263 & 1286 & 1191 & 1149 & 892 & 257 \\
& 0.7916 & 0.5990 & 0.1926 & 1136 & 1154 & 1078 & 899 & 691 & 208
\end{tabular}

Wage NOK 200

\begin{tabular}{llllllllll}
\hline Income & \multicolumn{3}{l}{ Probability of working } & \multicolumn{3}{c}{ Conditional mean hours } & \multicolumn{3}{c}{ Unconditional mean hours } \\
\hline & All & Public & Private & All & Public & Private & All & Public & Private \\
50,000 & 1.0000 & 0.8075 & 0.1925 & 1919 & 1925 & 1896 & 1919 & 1554 & 365 \\
100,000 & 1.0000 & 0.8051 & 0.1949 & 1887 & 1895 & 1853 & 1887 & 1526 & 361 \\
200,000 & 0.9995 & 0.8006 & 0.1989 & 1836 & 1848 & 1788 & 1835 & 1480 & 356
\end{tabular}

Wage NOK 300

\begin{tabular}{llllllllll}
\hline Income & \multicolumn{3}{l}{ Probability of working } & \multicolumn{3}{c}{ Conditional mean hours } & \multicolumn{3}{c}{ Unconditional mean hours } \\
\hline \multirow{3}{*}{50,000} & All & Public & Private & All & Public & Private & All & Public & Private \\
100,000 & 1.0000 & 0.8034 & 0.1966 & 2096 & 2088 & 2129 & 2096 & 1678 & 418 \\
200,000 & 1.0000 & 0.8040 & 0.1960 & 2083 & 2076 & 2112 & 2083 & 1669 & 414 \\
& 1.0000 & 0.8043 & 0.1957 & 2063 & 2058 & 2086 & 2063 & 1655 & 408
\end{tabular}




\section{Appendix F. Labor supply curves}

Figure F.1. a-d. Uncompensated and compensated unconditional expected hours, public and private sector. Woman aged 30.
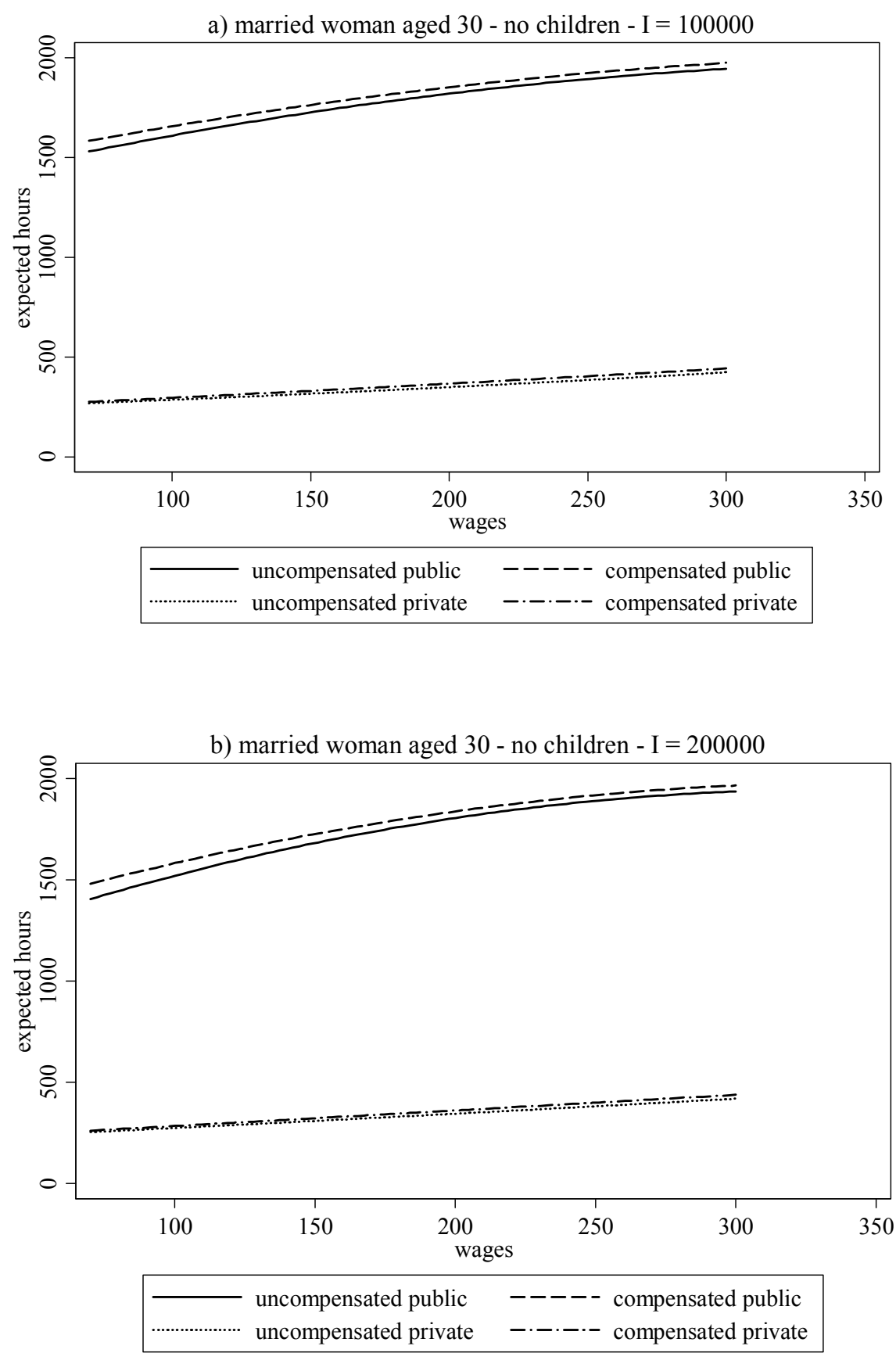

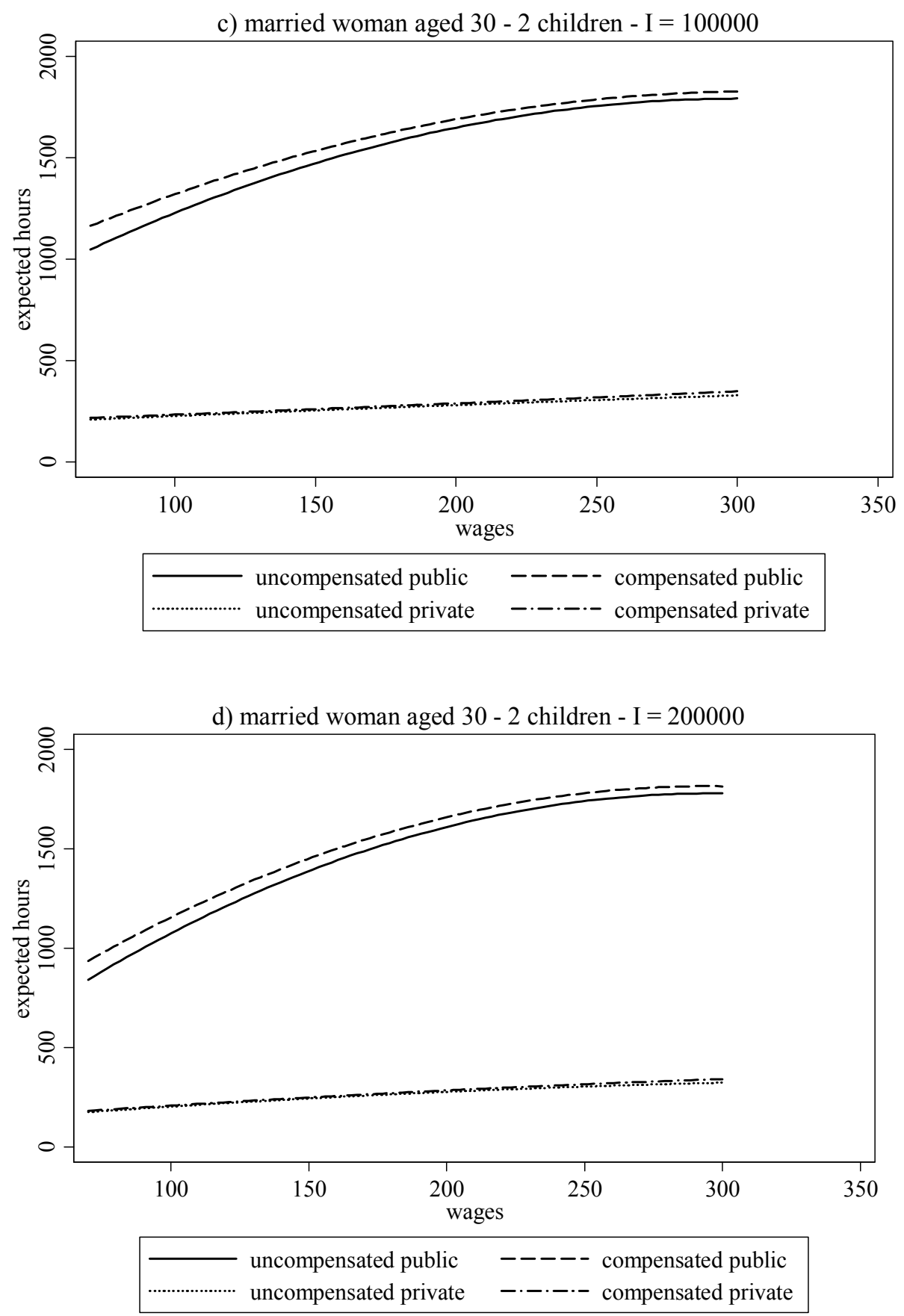
Figure F. 2.a-d. Uncompensated and compensated unconditional expected hours, public and private sector: woman aged 40 .
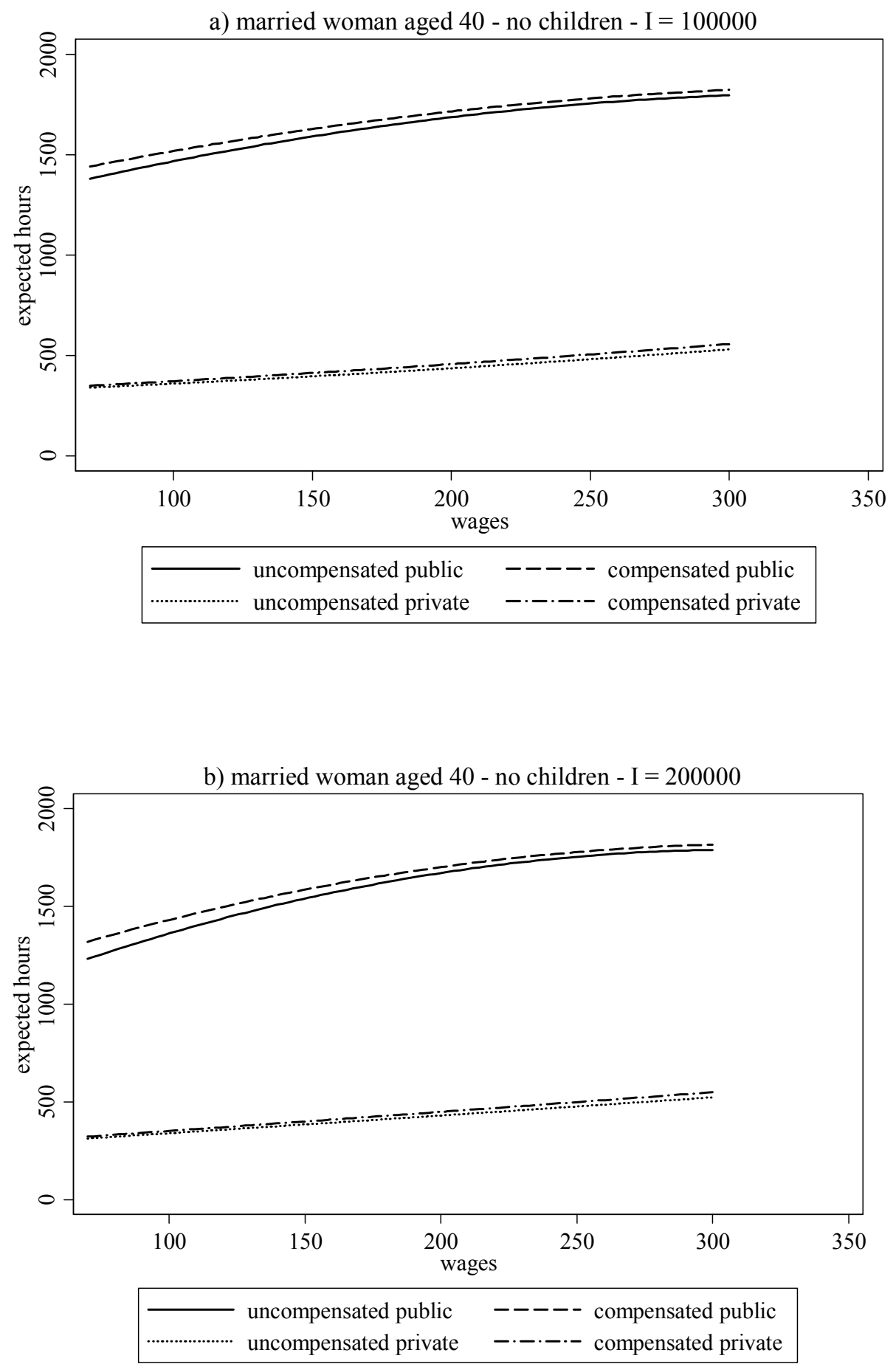

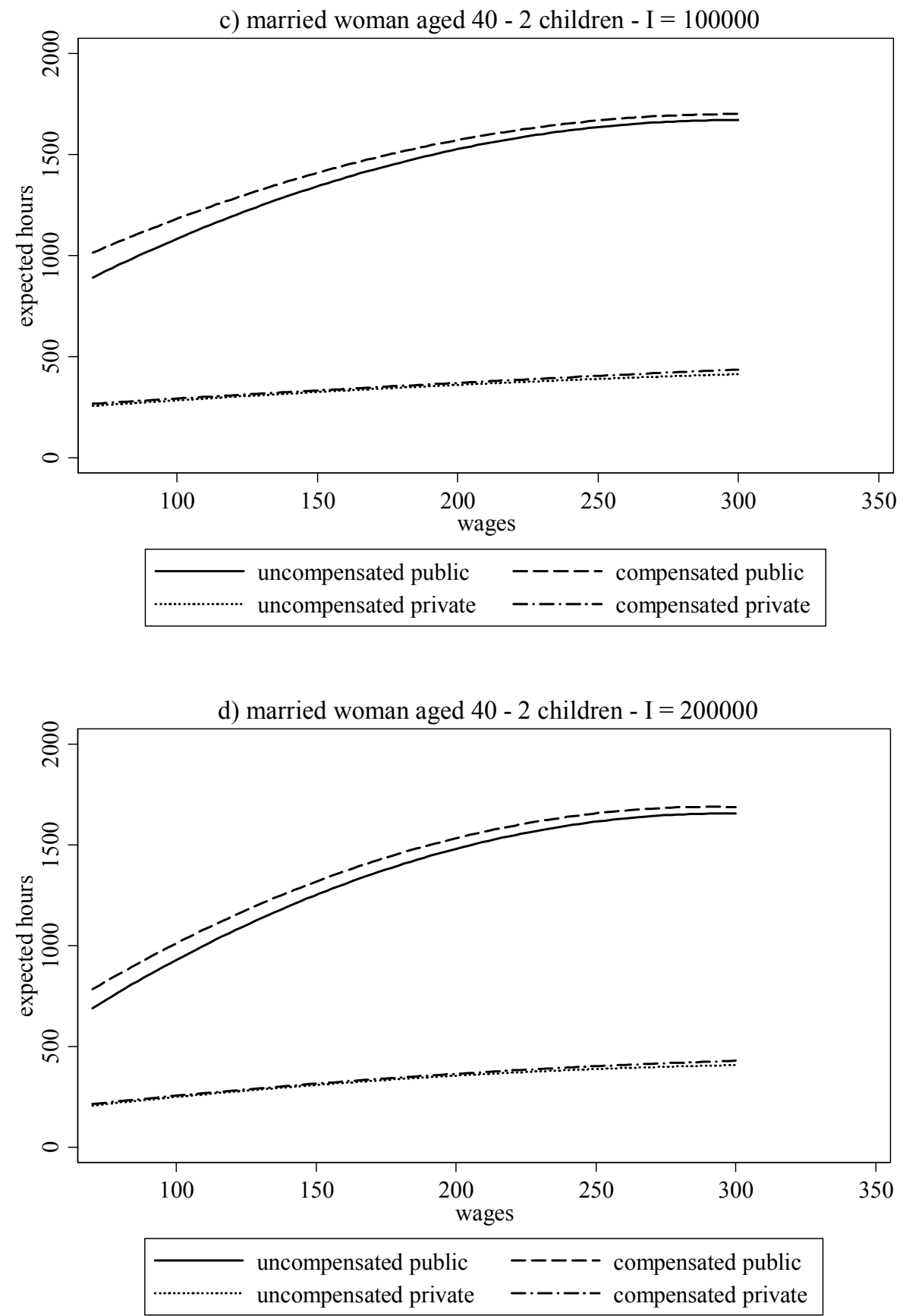
Figure F.3. a-d. Uncompensated and compensated unconditional expected hours, both sectors: woman aged 30 .
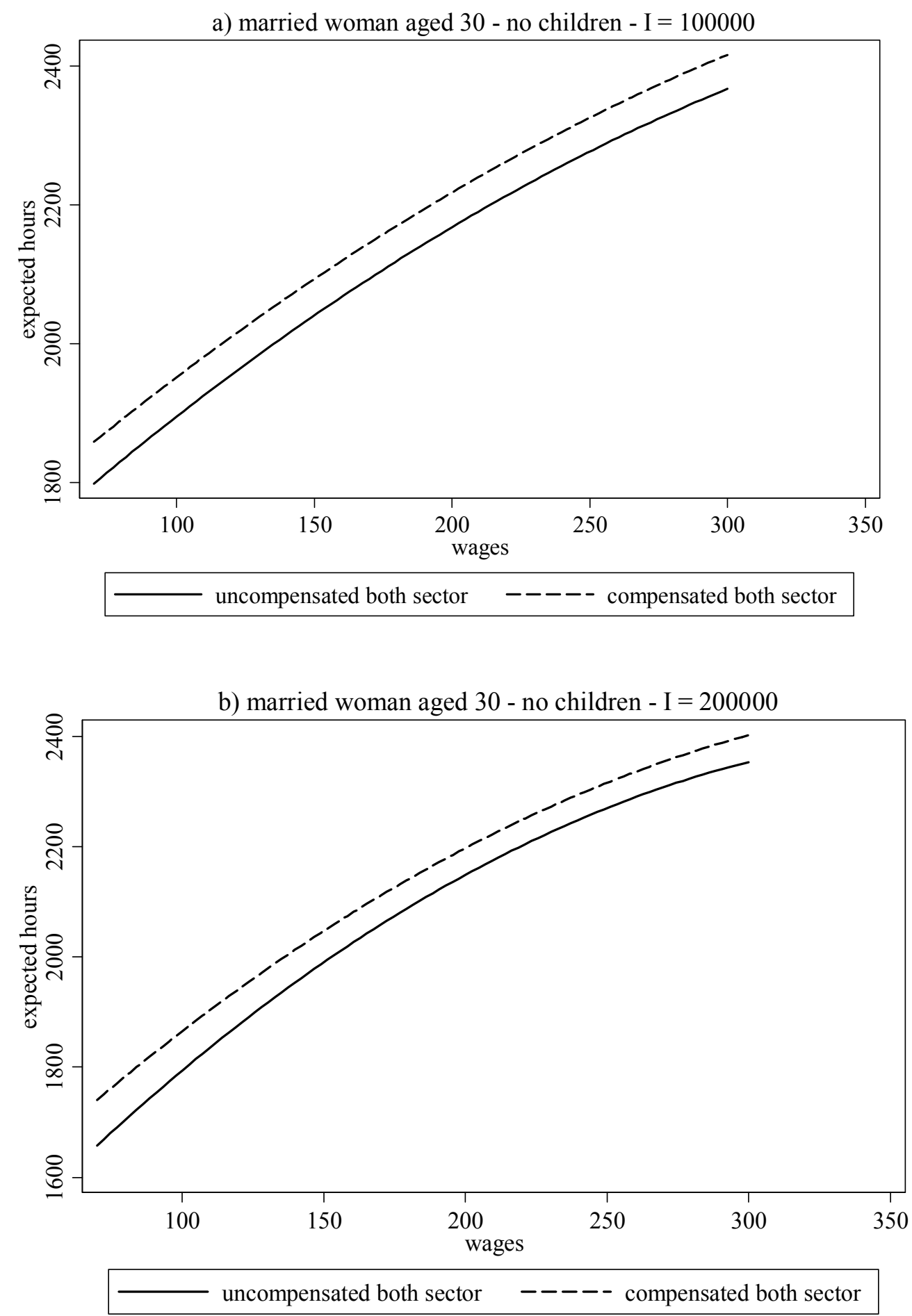

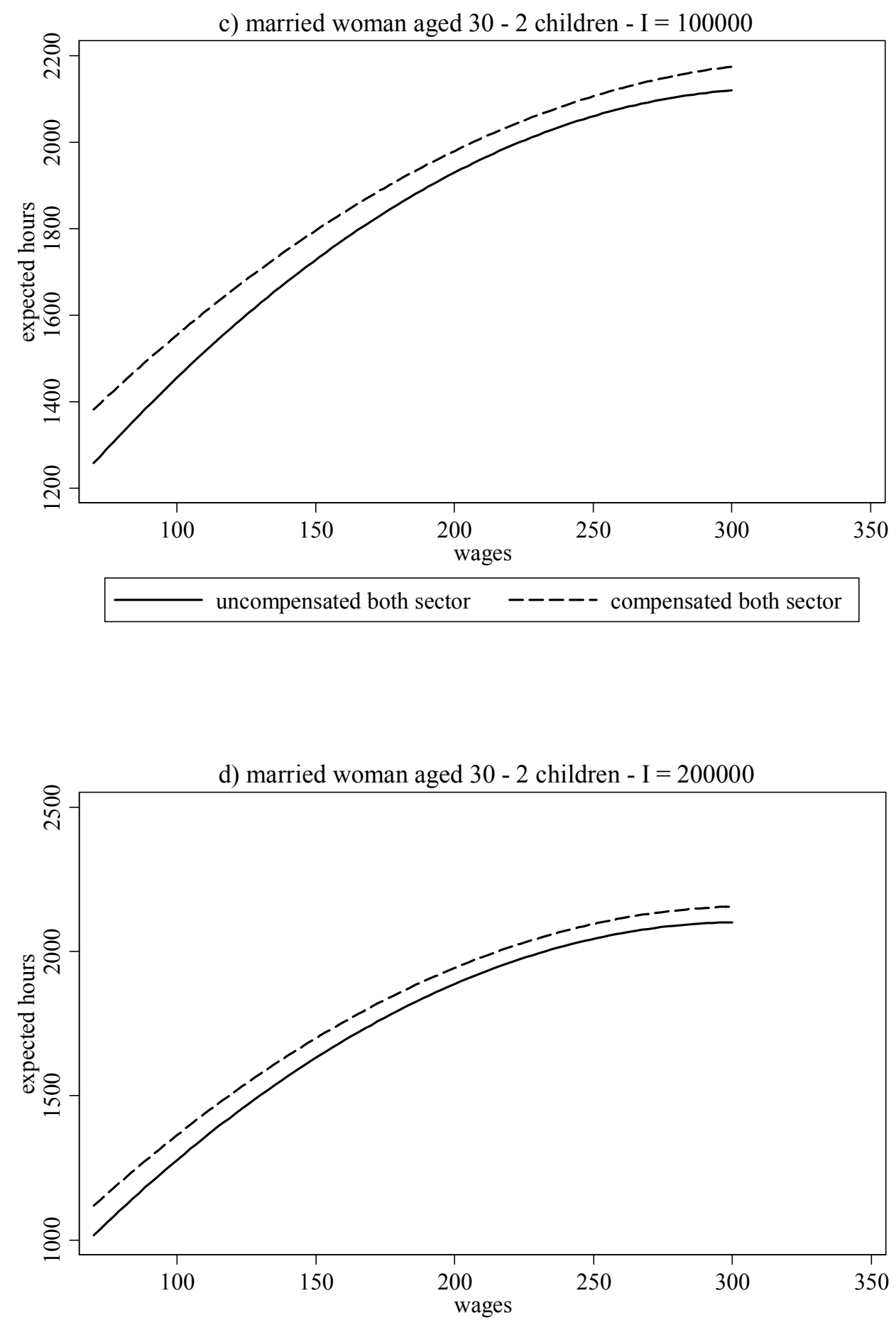

uncompensated both sector $\quad-----$ compensated both sector 
Figure F.4.a-d. Uncompensated and compensated unconditional expected hours, both sector: woman aged 40 .
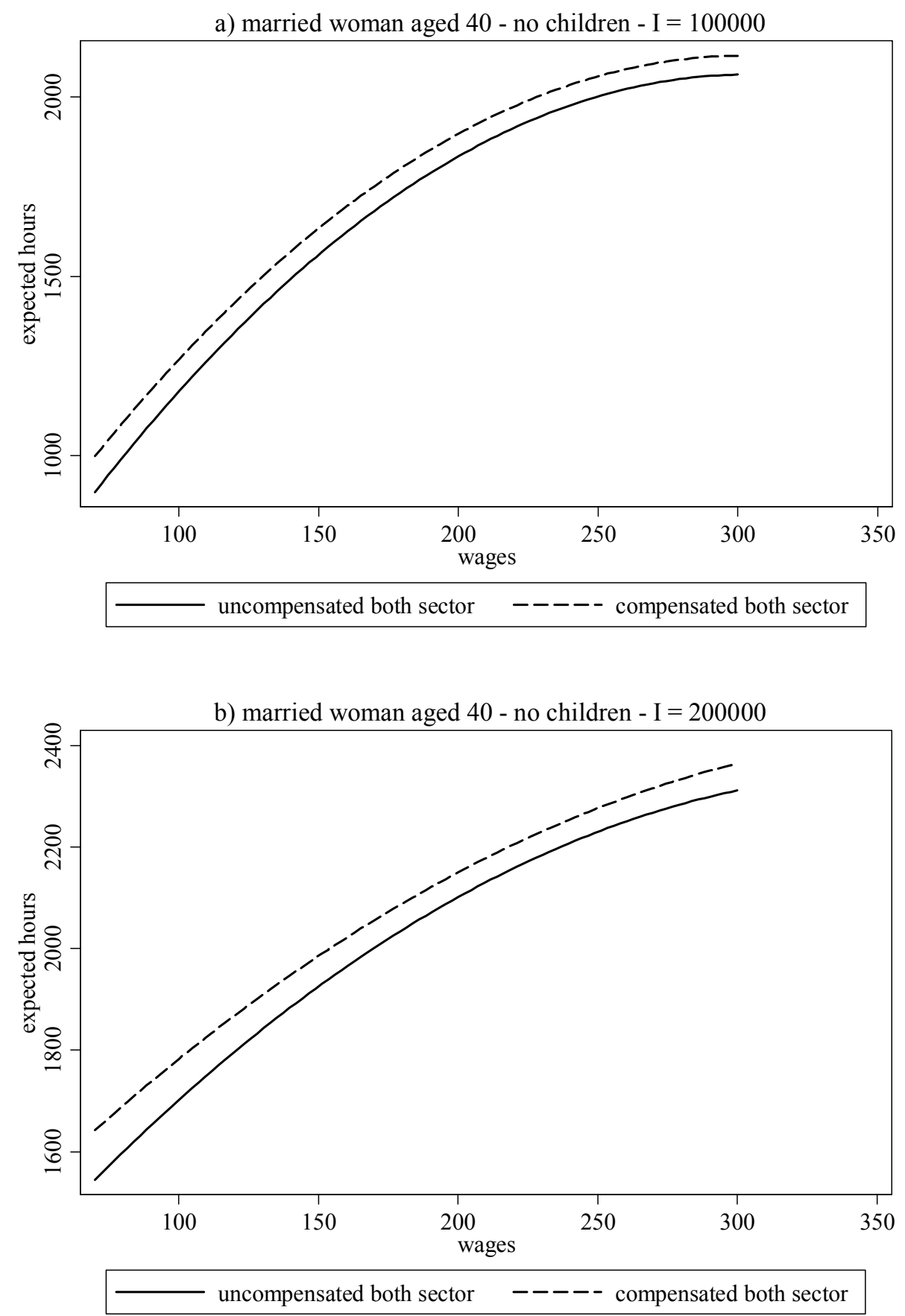


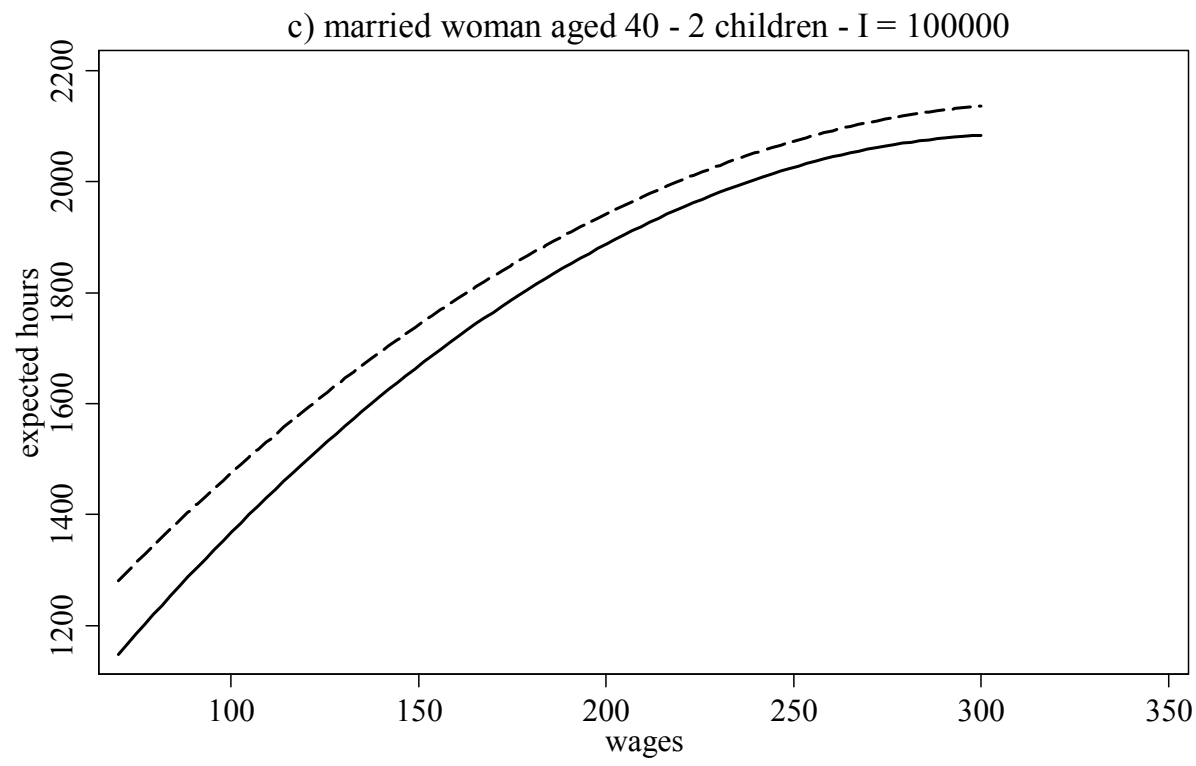

uncompensated both sector $\quad-----$ compensated both sector

d) married woman aged $40-2$ children $-I=200000$

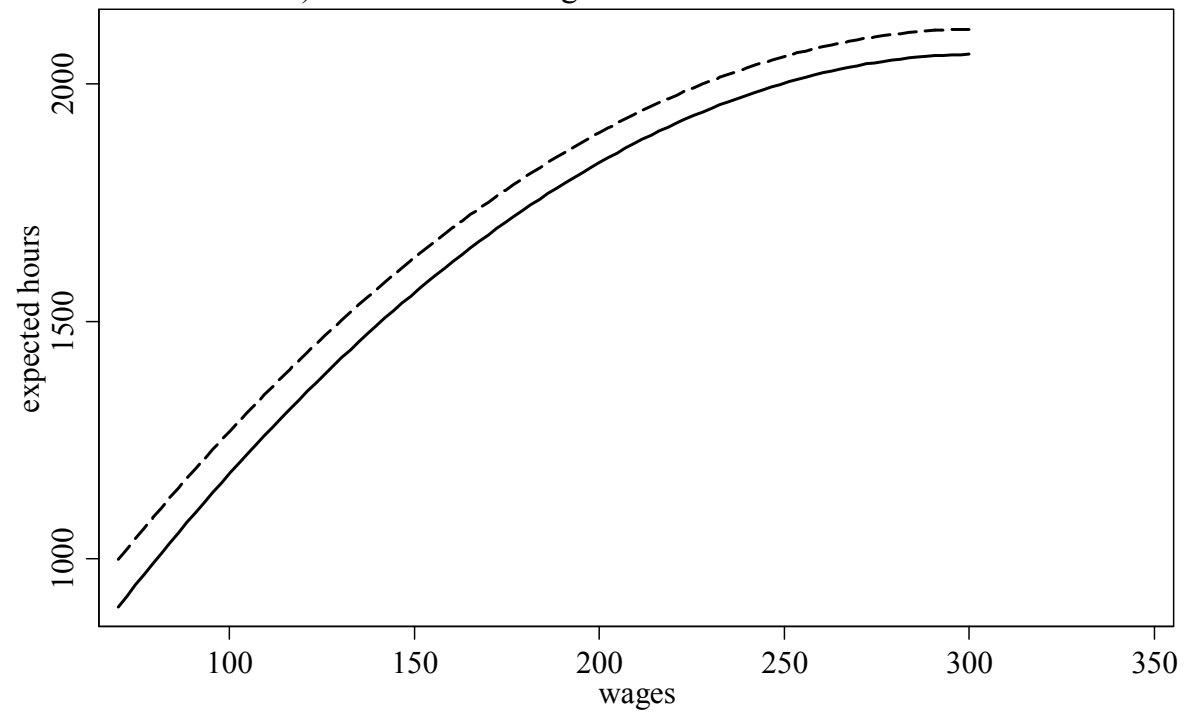

uncompensated both sector $\quad-----$ compensated both sector 
